c. 4

\title{
UNIAXIAL STRAIN TESTING OF SOILS FOR BLAST-ORIENTED PROBLEMS \\ by
}

J. G. Jackson, Jr.

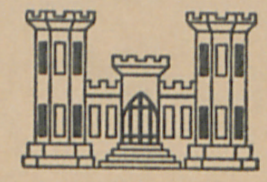

September 1968

Sponsored by

Defense Atomic Support Agency

Conducted by

U. S. Army Engineer Waterways Experiment Station CORPS OF ENGINEERS

Vicksburg, Mississippi 


\title{
UNIAXIAL STRAIN TESTING OF SOILS FOR BLAST-ORIENTED PROBLEMS \\ by \\ J. G. Jackson, Jr.
}

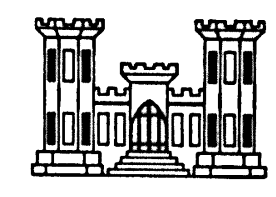

September 1968

\author{
Sponsored by \\ Defense Atomic Support Agency
}

Conducted by

U. S. Army Engineer Waterways Experiment Station CORPS OF ENGINEERS

Vicksburg, Mississippi

ARMY-MRC VICKEBURG. MIBS.

THIS DOCUMENT HAS BEEN APPROVED FOR PUBLIC RELEASE AND SALE; ITS DISTRIBUTION IS UNLIMITED 
THE CONTENTS OF THIS REPORT ARE NOT TO BE USED FOR ADVERTISING, PUBLICATION, OR PROMOTIONAL PURPOSES. CITATION OF TRADE NAMES DOES NOT CONSTITUTE AN OFFICIAL ENDOKSEMENT OR APPROVAL OF THE USE OF SUCH COMMERCIAL PRODUCTS. 


\section{Foreword}

The uniaxial strain test equipment and the special soil specimen preparation procedures described herein were developed in conjunction with research on propagation of ground shock through soils being conducted by personnel of the Soils Division, U. S. Army Engineer Waterways Experiment Station (WES), for the Defense Atomic Support Agency.

This paper is based on material assembled for discussion at the Session on Testing of Soils at High Pressure sponsored by the ASTM Southeastern District Committee and the ASCE Georgia Section Soil Mechanics Group at the ASTM National Fall Meeting, October 4, 1968.

This paper was prepared by Mr. J. G. Jackson, Jr., Chief, Impulse loads Section, Soil Dynamics Branch, WES, under the general supervision of Messrs. W. J. Turnbull and A. A. Maxwell, Chief and Assistant Chief, respectively, WES Soils Division.

Director of the WES during the preparation and publication of this paper was COL Ievi A. Brown, CE. Technical Director was Mr. J. B. Tiffany. 


\section{Contents}

Page

Foreword ........................ v

Conversion Factors, British to Metric Units of Measurement . . . . ix

Surmary. . . . . . . . . . . . . . . . . . . xi

Introduction ..................... I

Uniaxial Strain Testing Equipment. . . . . . . . . . . 1

10-in.-diam device ............... 2

5-in.-diam device. . . . . . . . . . . . . 3

Adjustable lateral stress device . . . . . . . . . . 3

15,000-psi device. . . . . . . . . . . . . 4

Specimen Preparation Procedures. ............. 5

Laboratory-prepared specimens. . . . . . . . . . 5

Undisturbed field specimens. . . . . . . . . . . 5

Typical Test Results .................. 8

Cohesionless specimen prepared by raining (10-in.-

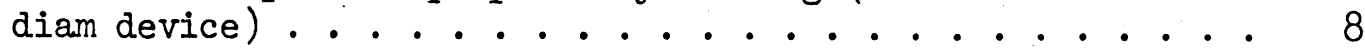

Cohesive specimen prepared by dynamic compaction

(10-in.-diam device). . . . . . . . . . . . 8

Undisturbed Shelby-tube ring specimen (10-in.-diam device). . 9

Undisturbed Shelby-tube ring specimen (5-in.-diam device). . . 9

Undisturbed 3.6-in.-diam ring specimen (5-in.-diam device) . . 10

Undisturbed Shelby-tube ring specimen (adjustable lateral

stress device)................... 10

Conclusion . . . . . . . . . . . . . . . 10

Figures $1-28$ 


\section{Conversion Factors, British to Metric Units of Measurement}

British units of measurement used in this report can be converted to metric units as follows:

Multiply

inches
pounds
pounds per square inch
pounds per cubic foot
kips
tons

\begin{tabular}{l}
$\frac{1}{\text { By }}$ \\
\hline 2.54 \\
0.45359237 \\
0.070307 \\
16.0185 \\
453.59237 \\
907.185
\end{tabular}

To Obtain centimeters

kilograms

kilograms per square centimeter

kilograms per cubic meter

kilograms

kilograms 


\section{Summary}

The soil stress-strain relations of most interest for blast-oriented problem analyses are those obtained from tests in which controlled impulsive stresses are applied to soil specimens confined so as to deform in an undrained state of uniaxial strain. Unique uniaxial strain test equipment and procedures currently in use at the U. S. Army Engineer Waterways Experiment station for conducting both fundamental research studies and investigations of field sites are briefly described herein. Special procedures for producing laboratory-prepared and undisturbed test specimens of high quality are also described along with test results obtained from a wide variety of soil types. 


\section{UNIAXIAL STRAIN TESTING OF SOILS FOR BLAST-ORIENTED PROBLEMS}

\section{Introduction}

1. A major factor in the design and analysis of hardened defense installations is the assessment of ground stresses and motions to which the structures will be subjected. As the ground shock moves from the explosion to the structure, its energy is attenuated by the soils through which it propagates. Thus, there is a continuing requirement to establish both the functional form and the quantitative definition of various soil constitutive relations or stress-strain properties, particularly those which most affect the propagation and attenuation of high-intensity stress waves. For these blast-oriented problems, the most useful stress-strain relations currently being generated are those from controlled impulsive stresses applied to undisturbed soil specimens confined so as to deform in an undrained state of uniaxial strain.

2. The purpose of this paper is to briefly describe the unique uniaxial strain test equipment currently in use at the U. S. Army Engineer Waterways Experiment Station (WES) as well as some of the special sample preparation and testing techniques that have been developed in conjunction with it. Typical test results are also presented.

\section{Uniaxial Strain Testing Equipment}

3. The WES facilities for uniaxial strain soil property testing consist of two gas-actuated ram loaders capable of applying variableintensity impulsive loads that are characteristic of airblasts and various test chambers which convert the ram load to a uniform axial pressure applied to the top surface of a laterally constrained soil specimen. The WES Dynapak ram loader in position for a uniaxial strain test is shown in fig. 1. The Dynapak loader is used to apply preprogrammed dynamic loads of up to $25 \mathrm{kips}^{*}$ with rise times to peak load ranging from 1 to $40 \mathrm{msec}$,

* A table of factors for converting British units of measurement to metric units is presented on page ix. 
hold times from 0 to $\infty$, and decay times from 25 to $1000 \mathrm{msec}$; details of its design and operating characteristics have been published previously.* A new SECO loader has recently been acquired which can be used to apply similar impulsive loads of up to $100 \mathrm{kips}$; this loading machine is shown in fig. 2 .

10-in.-diam device

4. A cutaway drawing of the WES 10-in.-diam uniaxial strain device is shown in fig. 3. Load from the ram is transmitted through three columns to a piston which compresses a fluid to uniformly load the soil specimen. Pressure is measured in the fluid so that o-ring friction and piston inertia do not create applied stress measurement problems. The specimen, is kept thin or wafered in order to minimize sidewall friction effects and to permit a uniform state of stress to develop within the specimen due to multiple internal stress reflections. 'Specimens are 10 in. in diameter and may be either 1 in. or 2-1/2 in. thick, depending upon the anticipated compressibility and gradation of the soil being tested. Surface deflections are measured at four points across the specimen using Iinear variable differential transformers (LVDT's); speciai provisions have been incorporated into this measurement system to eliminate core rod friction and chamber fluid leakage while permitting calibration of the magnetically sensitive coils in the actual test environment. Strain is calculated from the surface deflection and the height of the soil chamber by the usual assumption that strain within the specimen is uniform from top to bottom.

5. The 10-in.-diam device is extremely versatile; it can be used to conduct static and dynamic tests for purposes of fundamental research as -well as for practical engineering applications, on either laboratoryprepared or field-sampled specimens of all soil types, under pressures

* R. W. Cunny and R. C. Sloan, "Dynamic Loading Machine and Results of Preliminary Small-Scale Footing Tests," American Society for Testing and Materials Special Technical Publication No. 305, 1961; and J. G. Jackson, Jr., and P. F. Hadala, "Dynamic Bearing Capacity of Soils; Report 3, The Application of Similitude to Small-Scale Footing Tests," Technical Report No. 3-599, U. S. Army Engineer Waterways Experiment Station, Vicksburg, Mississippi, Dec 1964. 
ranging up to 2000 psi. Design and evaluation of this device and its highquality performance have been described in considerable detail by Schindler in his Ph. D. dissertation;* an abbreviated version of his dissertation is also in publication. $x \cdot *$

5-in.-diam device

6. When a soil sample is removed from the ground its geostatic overburden stresses are relieved resulting in some volumetric expansion of the sample. Since a principal boundary condition of the uniaxial strain test involves the absence of strain in the lateral direction, special procedures (to be described later) have been devised for preparing test specimens without extruding them from the 1/8-in.-wall-thickness steel tubes used to extract, the samples from the field site. Although the lateral expansion of such specimens is restricted, they can readily expand axially and thus, prior to live loading, must be recompressed under a static axial pressure approximately equal to the geostatic overburden stress at the depth from which the sample was obtained.

7. The 5-in.-diam uniaxial strain device is simply an adaptation of the basic 10-in.-diam device modified for the express purpose of testing undisturbed specimens lathed from 5-1/4-in.-OD by 5-in.-ID Shelby tubes. A cutaway drawing of the 5-in.-diam device is shown in fig. 4. Doughnutshaped inserts were machined for the 1 - and 2-1/2-in.-deep soil containers to receive the shelby-tube ring specimens; a similarly shaped insert was made to adapt the f'luid container for a 5-in.-diam piston loading assembly. Jew upper container and LVDT coil. support plates were also required. Strain measurement is made by a single, centrally located LVDT. Adjustable lateral stress device

8. Calculations for two-dimensional problems involve not only vertical stresses and motions but also radial or lateral response.

* L. Schindler, "Design and Evaluation of a Device for Determining the One-Dimensional Compression Characteristics of Soils Subjected to Tmpulse-Type Loads," Ph. D. thesis submitted to the University of Illinois, Urbana, Illinois, 1968.

** L. Schindler, "An Improved Facility for Testing Soils in OneDimensional Compression," paper submitted for publication in Proceedings of the Symposium on Wave Propagation and Dynamic Properties of Earth Materials, University of New Mexico, Albuquerque, New Mexico, May 1967. 
Therefore, information relating axial and radial stresses is a necessary input to such calculations. The ratio between radial stress and axial stress for the condition of zero radial strain (i.e., the state of uniaxial strain) defines an extremely useful soil property called the coefficient of earth pressure at rest $\left(\mathrm{K}^{\circ}\right)$. The WES adjustable lateral stress device was constructed to provide quantitative data about $\mathrm{K}^{\circ}$ for undisturbed soils subjected to high-pressure loading and unloading under static conditions.

9. The device is a relatively simple modification of the 5-in.diam uniaxial strain device previously described; a cutaway drawing is shown in fig. 5. When the soil container insert is in place, a sealed chamber surrounds the Shelby-tube specimen. As the specimen is axially loaded, oil in the lateral pressure chamber is pressurized through an inlet in the base to prevent lateral expansion of the specimen; the lateral pressure can be relieved as necessary to prevent contraction of the specimen as the axial load is removed. The absence of lateral strain throughout the test is indicated by the "null" reading of a calibrated straingaged band placed around the Shelby-tube specimen.

15,000-psi device

10. For nuclear weapons effects related problems, there is an urgent need for a capability to determine meaningful soil constitutive properties under controlled states of stress much higher than the 2000-psi capability of the previously described devices. In response to this need, a uniaxial strain device for static and dynamic testing of 5-in.-diam undisturbed specimens at pressures of up to 15,000 psi is now being constructed.

11. A cutaway drawing of the 15,000-psi device is shown in fig. 6 . Although this device is similar in principal to other WES devices, there are perhaps three distinguishing features which should be pointed out. First, since at 15,000-psi pressures even steel deforms significantly, the chamber wall thickness has been increased substantially to limit the radial strain and thus maintain an essentially uniaxial strain condition. The second factor results from the fact that one cannot generate 15,000 psi on a 5-in.-diam piston with a 100-kip loading machine. Thus, a force multiplier technique had to be devised wherein a loading piston smaller in 
diameter than the soil sample was used to pressurize the fluid chamber. The third and most crucial factor is that the unique LVDT strain measurement system currently being used with the other WES devices is not suitable for use at this extremely high pressure since the increased wall thickness required for the core housing would prevent an acceptable coil response. A new strain measurement system is being employed based on the principle of sensing a light beam that is emitted from a probe source within the fluid chamber and reflected from the surface of the test specimen. This measurement system along with the overall device assembly is currently unclergoing check-out and eviluation.

\section{Specimen Preparation Procedures}

12. As previously mentioned, tests may be conducted either on carefully controlled laboratory-prepared specimens for purposes of fundamental research or on undisturbed field specimens in conjunction with various site investigations.

Laboratory-prepared specimens

13. Prepared specimens of all soil types can be placed directly into the soil chamber by any of the conventional placement techniques. Cohesive soils, for instance, may be placed by dynamic compaction as shown in fig. 7. Dry sand specimens are prepared by a "raining" technique in which the sand falls through a series of holes uniformly distributed over the area of a circular plate, and then through a set of nine screens as shown in fig. 8. This WES-developed multiple-orifice sand sprinkler can repeatably produce exceptionally uniform specimens of specified relative density which are quite useful for test device calibration and evaluation purpose:: .

Undisturbed field specimens

14. Of much more practical interest, however, is the preparation and testing of undisturbed field specimens. The tube or ring containing the soil specimen is carefully machined and the specimen trimmed to a length exactly equal to the depth of the test device soil container. For tests in the 10-in.-diam device, the specimen and ring are placed in the 
center of the soil container and the volume between the ring and the container wall is filled with compacted sand as shown in fig. 9. Although the specimen container ring does not contact the wall of the basic soil container, the tendency of soil particles and moisture from the specimen to be squeezed out under the confining ring or for the confining ring to strain radially is resisted by the same pressure in the sand that surrounds it. For tests in the 5-in.-diam device, the specimen ring is restrained directly by the steel soil container insert or doughnut as shown in fig. 10. Thin steel shims are used as necessary to ensure a snug fit between the specimen ring and the doughnut insert.

15. Shelby-tube ring. A procedure for preparing uniaxial strain test specimens within Shelby-tube rings was devised to prevent specimen disturbance by extrusion from the sample tubes used to extract them from the field. However, disturbance from all aspects of preparation and trimming must be kept to a minimum; therefore, any metal cutting procedure used to get a specimen into the desired configuration must keep vibration and heat to a minimum.

16. The possible metal cutting procedures considered were (a) sawing with a band saw, (b) cutting on a lathe using a parting tool, and (c) machining on a lathe. Sawing with a band saw (a) caused an undesirable level of vibration and a relatively rough metal edge that would possibly mupture the rubber membrane sealing the specimen from the pressurized fluid; this option was therefore abandoned. The parting tool method (b) consisted of using the tool in a longitudinally fixed position on the lathe and rotating the Shelby tube fastened in the lathe chucks. As the tube rotated, the parting tool moved into the tube and made a cut directly into the Shelby tube, the width of the cut depending on the tool used. In this process, three faces of the tool contributed friction and caused rather severe chatter or vibration as well as heating of the sample; this method was also abandoned. The machining or turning technique (c) utilizes the same lathe setup as the parting tool method except that the machining tool makes a cut into the tube, and as the tube rotates, the tool moves longitudinally down the tube at a feed rate. In this process, only one face of the tool is in contact with metal. The lathe settings 
governing the operation are chuck revolutions per minute, feed rate of the machine tool down the lathe, and depth of each cut. These settings are controlled by the machine operator, and after extensive practice and investigation, settings have been found which result in an insignificant level of vibration and heat.

17. Fig. 11 shows a full-length (37-in.) Shelby tube chucked in the lathe for the first rough machine cut about $3 / 4 \mathrm{in}$. away from the desired finished edge of the test specimen. After the rough machine cut through the stieel tube, a wire saw is used to cut through the soil sample as shown in fig. 12. A separated rough-cut specimen, which is immediately coated with a protective wax, is shown in fig. 13. The rough-cut specimen is then chucked in the lathe and fine-machined on each end to obtain the desired final 1-in. or 2-1/2-in. dimension; this leaves a protective thickness of soil protruding from each end (see fig. 14) which is waxed prior to storage in a temperature- and humidity-controlled room. Finally, the specimen is trimmed flush with the machined faces of the shelby-tube ring as shown in fig. 15 just prior to the uniaxial strain test. This specimen preparation procedure has been extensively used and has proved to be quite satisfactory for most soils encountered during a variety of site investigations.

18. 3.6-in.-diam ring. The machining procedure described above is, of course, limited to soils with sufficient cohesive strength to remain stable during machining while chucked in a lathe and turned about a horizontal axis. Relatively cohesionless samples fall apart or pour out of. the steel shelby tube when the lathe cut is made. This limitation has been encountered in recent testing programs that included lacustrine deposits of fine sandy silts (ML) and silty sands (SM). Fortunately, however, good-quality 5-in.-diam undisturbed samples of these materials were obtained in the usual manner by immediate extrusion from the Shelby tube in the field, placement in 6-in.-diam cardboard containers, and encasement in paraffin or wax.

19. A 3.6-in.-diam laboratory sampler was designed for obtaining uniaxial strain test specimens from these 5-in.-diam wax-encased undisturbed soil samples. The sampler essentially consists of an inner specimen 
container ring surrounded by an outer driving sleeve and a beveled cutting shoe; a cutaway drawing of the sampler is shown in fig. 16. After the specimen has been extracted from the sample by jacking or advance trimming (fig. 17), the driving sleeve, small support sleeve, and upper collar are removed so that the top of the specimen is exposed (fig. 18). The soil is then trimmed flush with the top of the 3.6-in.-diam specimen container ring (fig. 19), and a uniaxial strain device adapter is placed over it (fig. 20). Supported by the adapter, the specimen is then inverted, the beveled cutting shoe, large support sleeve, and lower collar are removed, and the second exposed soil surface is trimmed flush with the specimen. container ring and test device adapter (fig. 2l). Fig. 22 shows the 1-in.high by 5-1/4-in.-diam adapter containing a 0.9-in.-deep by 3.6-in.-diam. soil specimen just prior to its insertion into the soil container for the previously described 5-in.-diam uniaxial strain test device.

\section{Typical Test Results}

20. The following uniaxial strain test results were extracted from six different laboratory investigations conducted by WES within the last two years. They were selected to include a wide variety of soil types tested using each of the previously described uniaxial strain test devices and specimen preparation techniques.

Cohesionless specimen pre-

pared by raining (10-in.-diam device)

21. The soil for this dynamic test was an air-dried, uniform, fine sand (SP), locally referred to as Reid-Bedford model sand. It was placed in the 10-in.-diam by 1.0-in.-deep soil container by the raining technique, resulting in a relative density $\left(D_{r}\right)$ of 93.2 percent. The test results are shown in fig. 23 and include the actual applied stress and strain response time-histories along with the composite stress-strain relation during both loading and unloading phases.

Cohesive specimen prepared by dynamic compaction (10-in.-diam device)

22. The soil for this dynamic test was a light tan, sandy clay (CL) 
obtained from Fort Belvoir, Virginia. It was air-dried, sieved through a No. 4 sieve, mixed with water to obtain a water content of 10.6 percent, and compacted in the 10-in.-diam by 1.0-in.-deep soil container (using 50 blows of a 10-1b hammer falling 18 in.) to a dry unit weight of 109.2 pcf. The test results are shown in fig. 24 ; in addition to the stress and strain time-histories and composite stress-strain curve, the initial water content (w), void ratio (e), degree of saturation (S), dry unit weight $\left(\gamma_{d}\right)$, and specific gravity $\left(G_{s}\right)$ are given as well as percentages by volume of air $\left(V_{a}\right)$, water $\left(V_{w}\right)$, and solids $\left(V_{s}\right)$ for the tested specimen.

Undisturbed Shelby-tube ring specimen (10-in.-diam device)

23. The soil for this dynamic test was an undisturbed tan silty clay (CL), locally known as Vicksburg loess, obtained from the site of a high-explosive tunnel demolition investigation. The 5-in.-diam by 1.0in.-high specimen was lathed from a Shelby-tube sample and placed in the center of the 10-in.-diam uniaxial strain soil test container; the volume between the specimen ring and the container wall was filled with dense sand to provide lateral restraint. The test results are given with the initial specimen data in fig. 25.

Undisturbed Shelby-tube

ring specimen (5-in.-diam device)

24. The specimen for this dynamic test was a saturated, gray, unoxidized sandy clay (CL) lathed from a Shelby-tube sample taken from a Minuteman site founded on glacial till near Hope, North Dakota. The 5in.-diam by 2-1/2-in.-high Shelby-tube ring specimen was placed in the steel doughnut insert to the basic soil container and pressurized statically with a 21.0-psi overburden-simulating pressure $\left(\sigma_{0}\right)$ prior to application of the live transient load. The results of the dynamic test are given with the initial specimen data in fig. 26. To indicate the effect of geostatic overburden stress, the initial portions of the stress-strain curves from two other unoxidized specimens obtained from the same boring and tested with preloads of $57 \mathrm{psi}$ and $93 \mathrm{psi}$ are also shown in fig. 26. 
Undisturbed 3.6-in.-diam

ring specimen ( 5 -in.-diam device)

25. The soil for this test was a slightly saturated, essentially nonplastic lake-bed deposit of brown sandy silt (ML) obtained in conjunction with the 500-ton, high-explosive Operation PRAIRIE FLAT at the Watching Hill Test Range, Defence Research Establishment, Suffield, Canada. The 3.6-in.-diam by 0.9-in.-high specimen was extracted from a 5-in.-diam, wax-encased undisturbed sample and fitted with its adapter into the 5-in.-diam uniaxial strain test device. The results of the 2000-psi dynamic test are given in fig. 27.

Undisturbed Shelbytube ring specimen (ad-: justable lateral stress device)

26. The soil for this test was a brown, oxidized sandy clay (CL) of glacial origin obtained from a Minuteman site near Valley City, North Dakota. The 5-in.-diam by 2-1/2-in.-high Shelby-tube ring specimen was placed in the adjustable lateral stress insert to the basic soil container and axially pressurized with 21 psi to simulate the vertical overburden stress relieved when the sample was removed from the ground. A lateral pressure of 15 psi was applied simultaneously to "null" the resulting lateral strain. The relations for vertical stress versus vertical strain and vertical stress versus lateral stress during static live-loading to $350 \mathrm{psi}$ and subsequent unloading are shown in fig. 28.

\section{Conclusion}

27. Unique equipment has been developed at WES for conducting uniaxial strain tests to provide stress-strain data for blast-oriented analyses. Special sample preparation techniques have been devised to repeatably produce uniform specimens of high quality for purposes of fundamental research and field specimens for various site investigations with a minimum of disturbance. Data obtained from a wide variety of soil types using this equipment and the se specimen preparation techniques have proved to be quite satisfactory. 


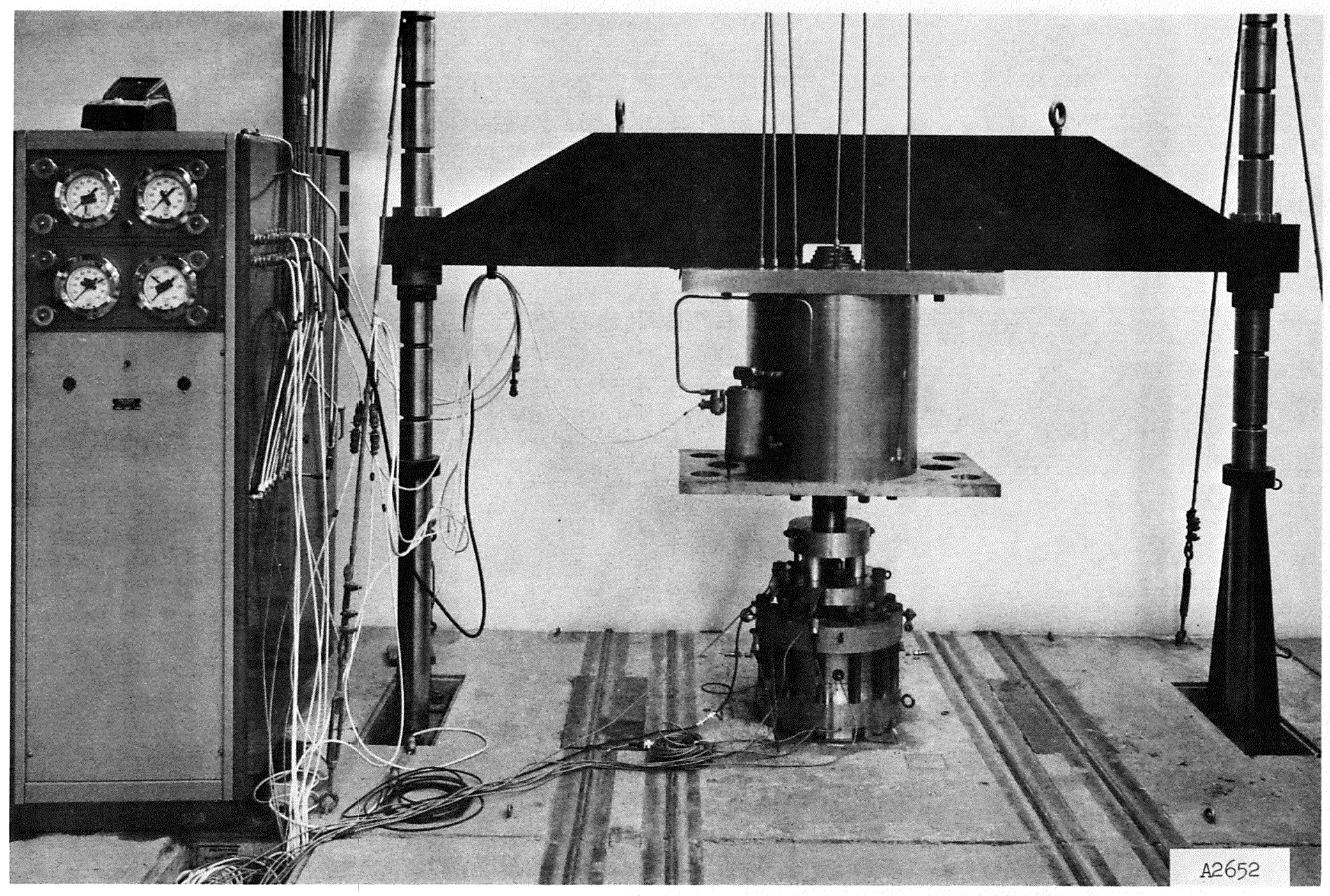

Fig. 1. Dynapak ram loader with 10-in.-diam uniaxial strain test device 


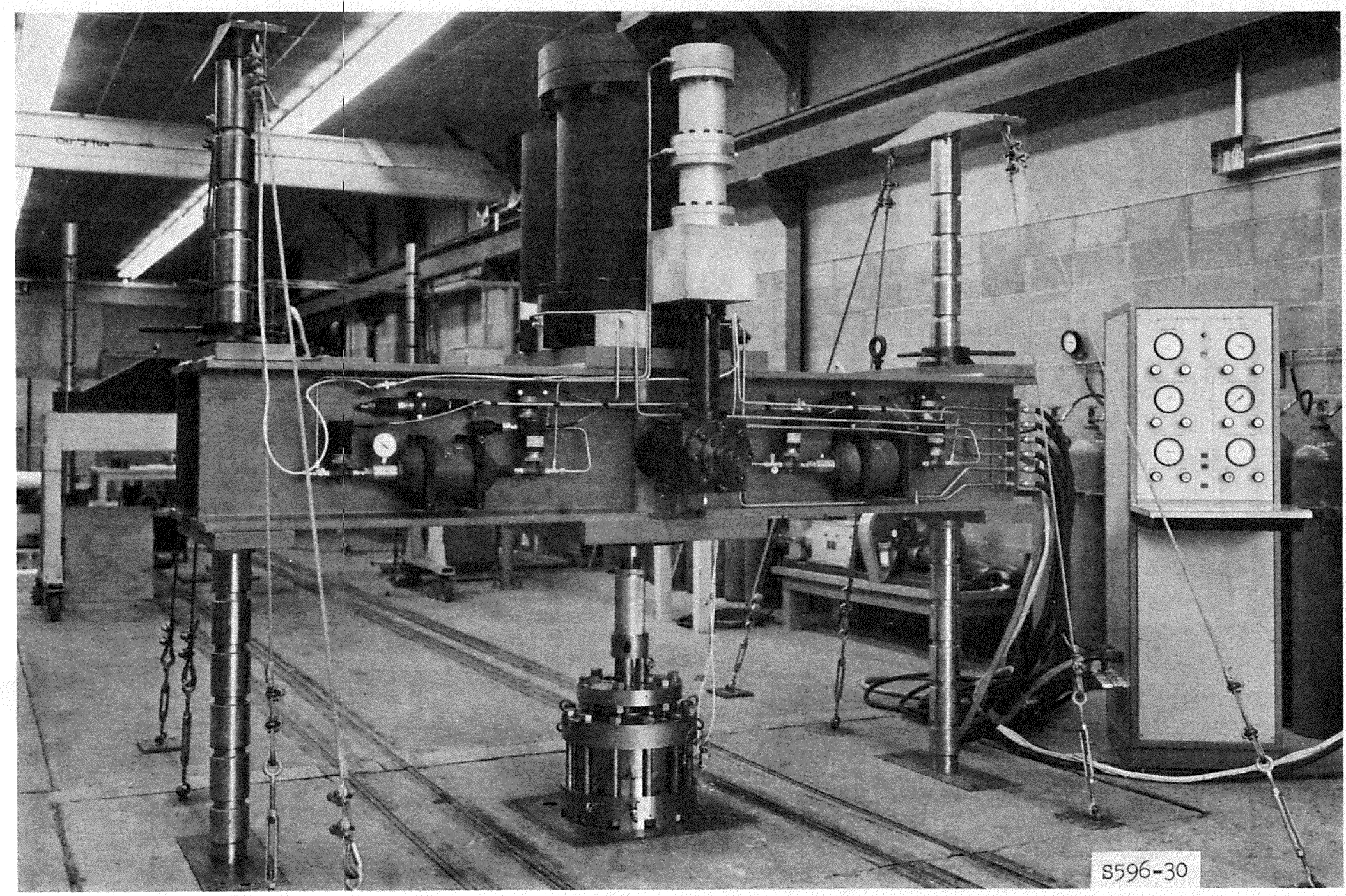

Fig. 2. SECO ram loader with 5-in.-diam uniaxial strain test device 

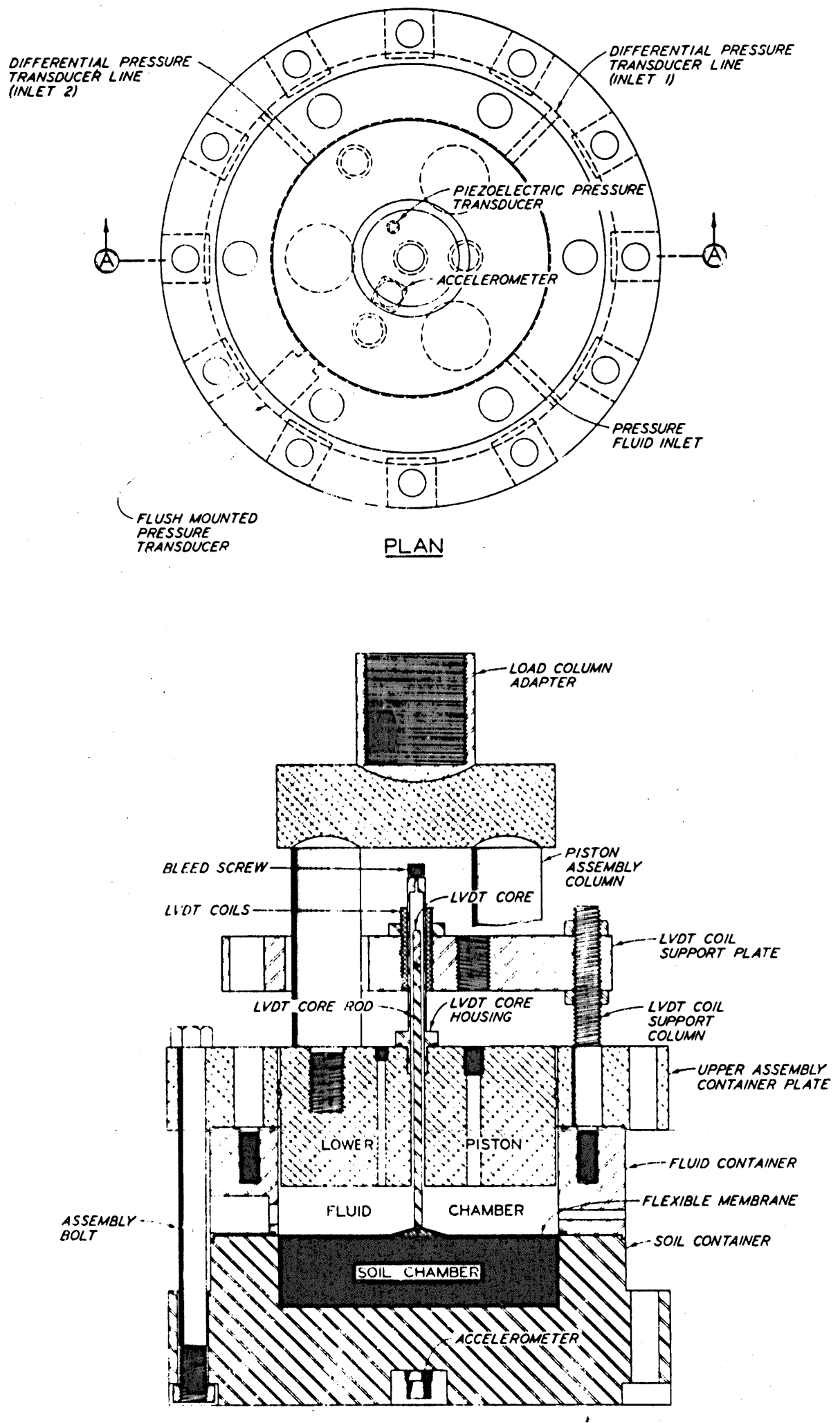

SECTION A-A

Fig. 3. 10-in.-di:am uniaxial strain test device 

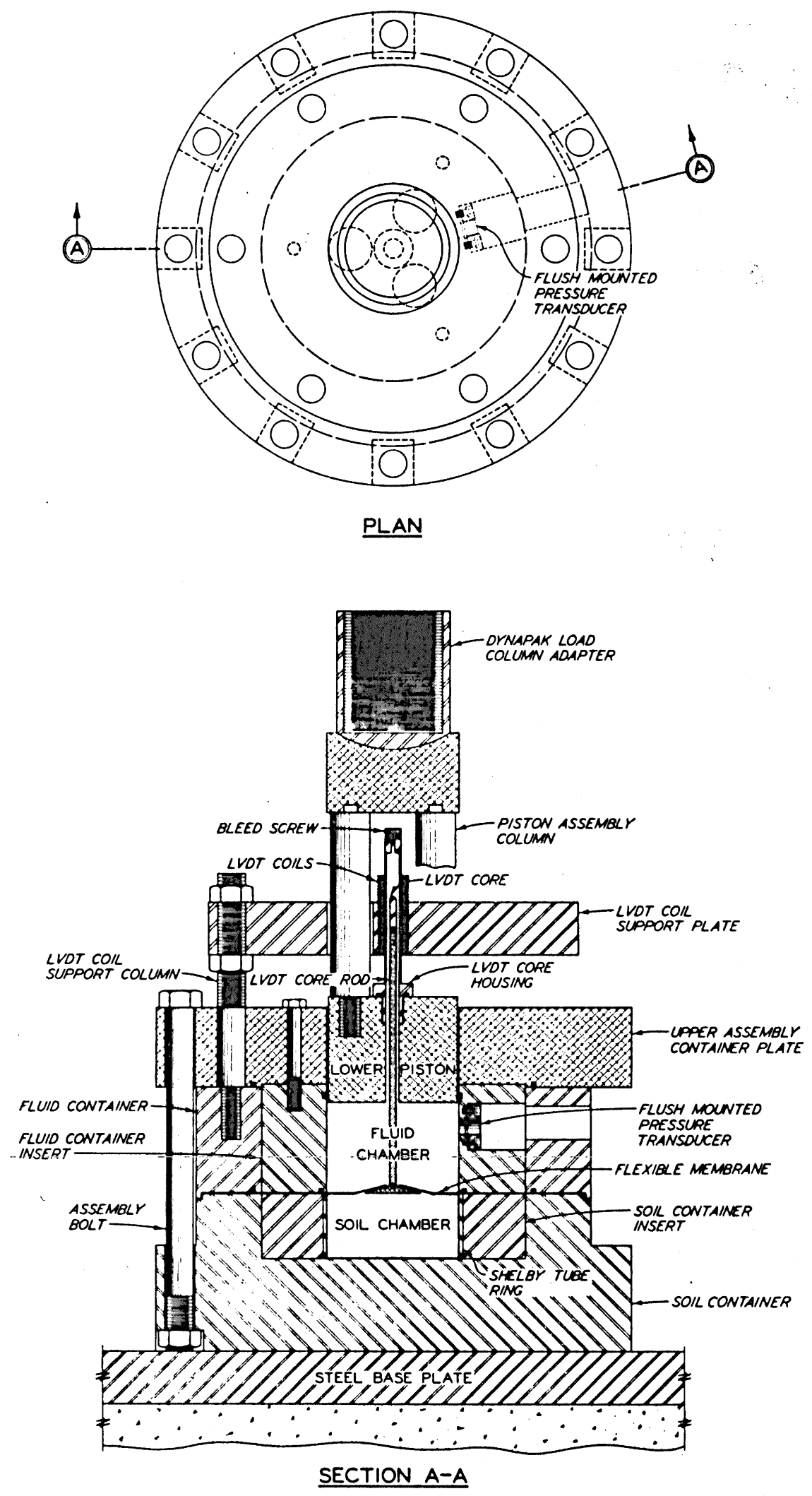

Fig. 4. 5-in.-diam uniaxial strain test device 


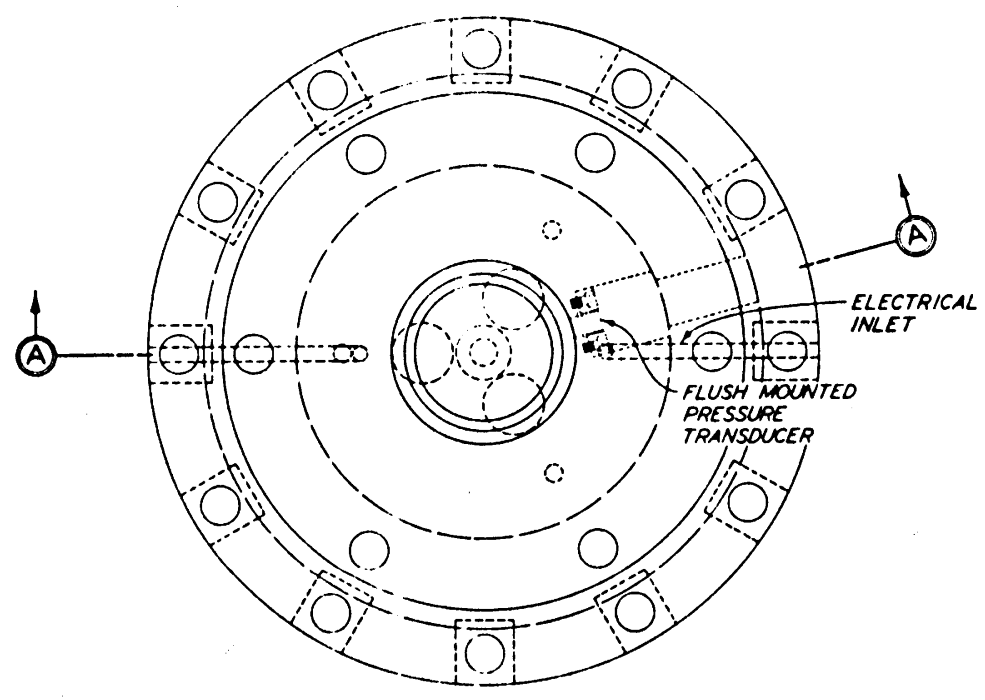

PLAN

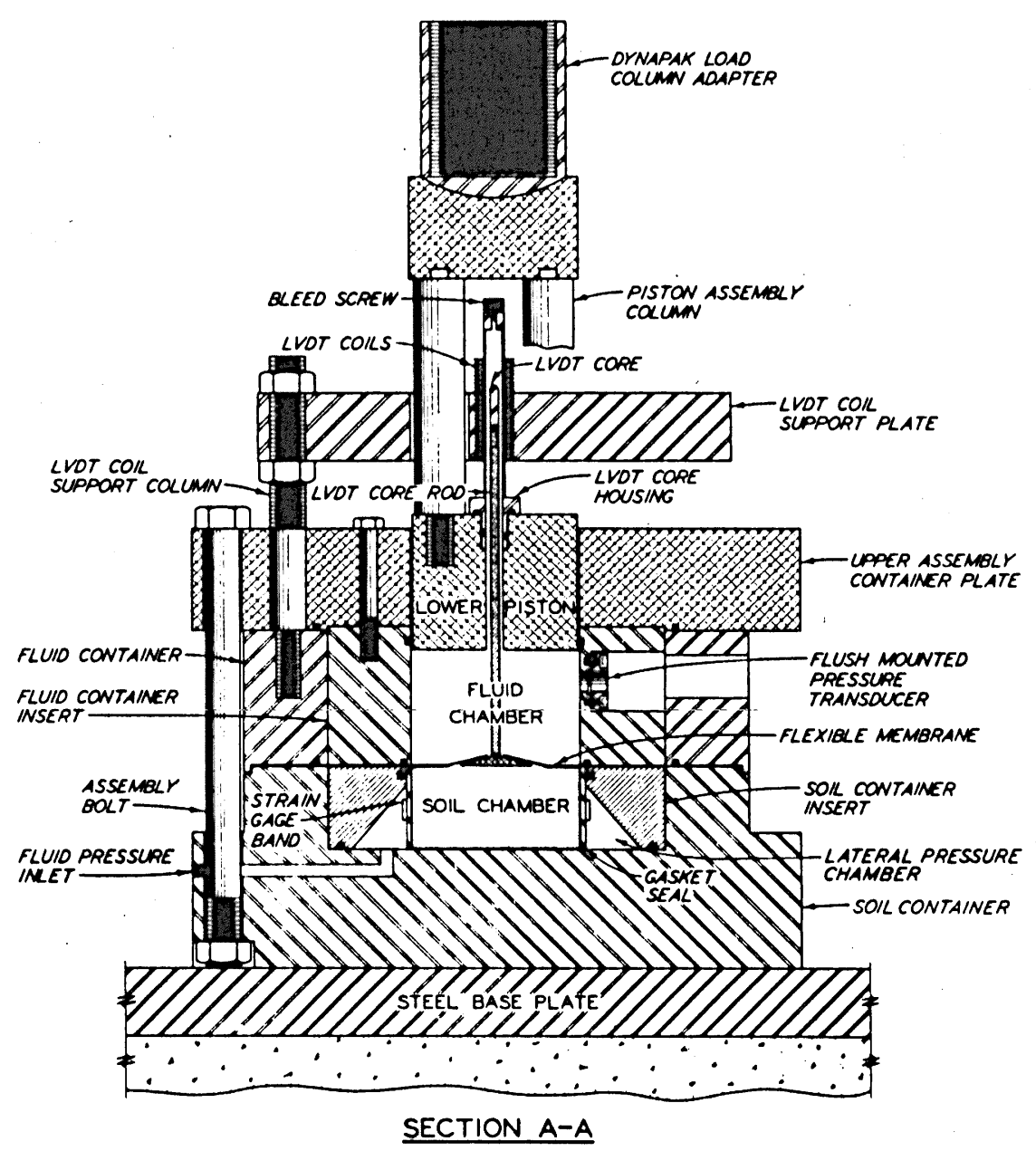

Fig. 5. Adjustable lateral stress uniaxial strain test device 


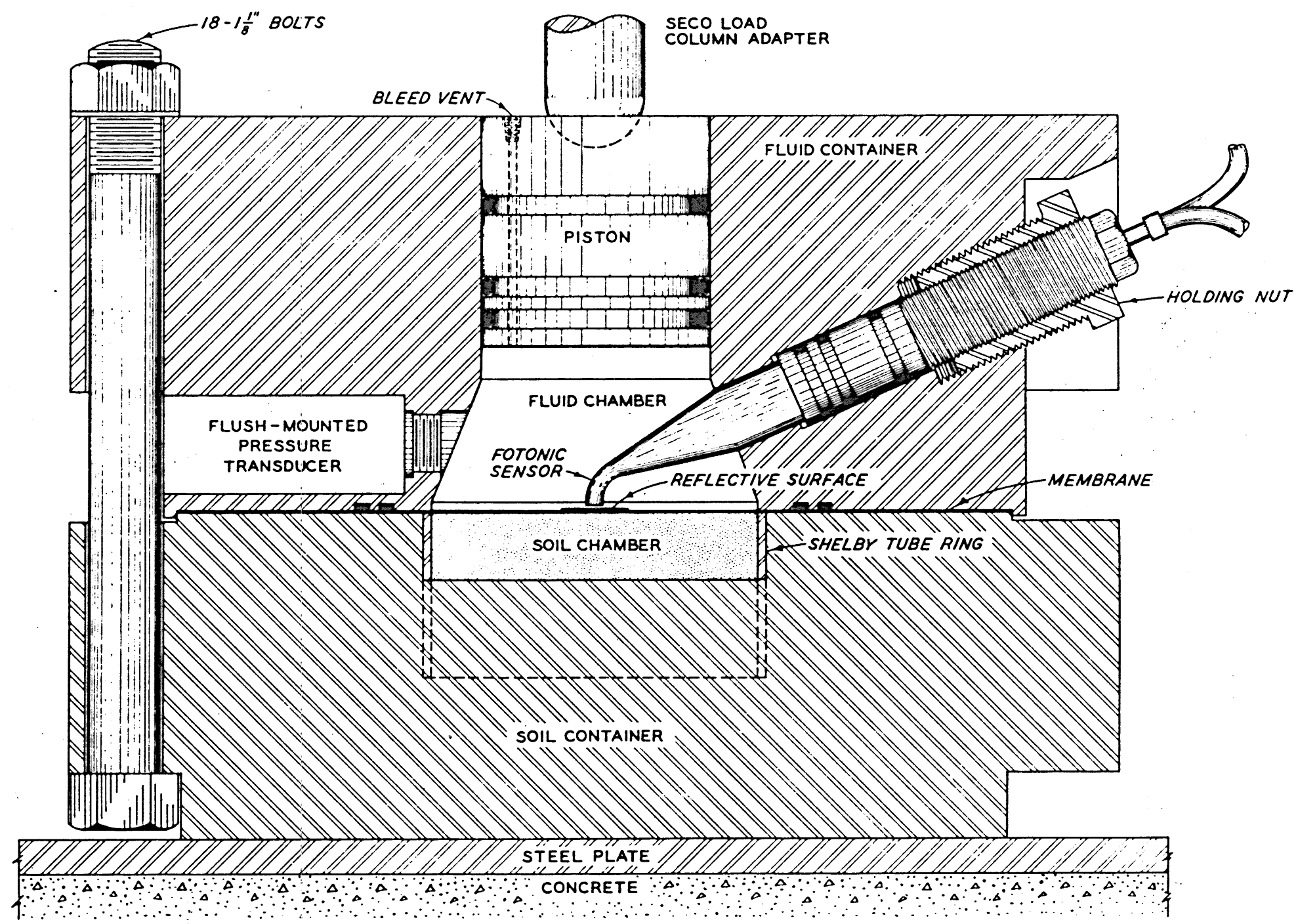

Fig. 6. 15,000-psi uniaxial strain test device 




Fig. 7. Dynamic compaction of cohesive specimen 




Fig. 8. Raining of dry sand specimen 


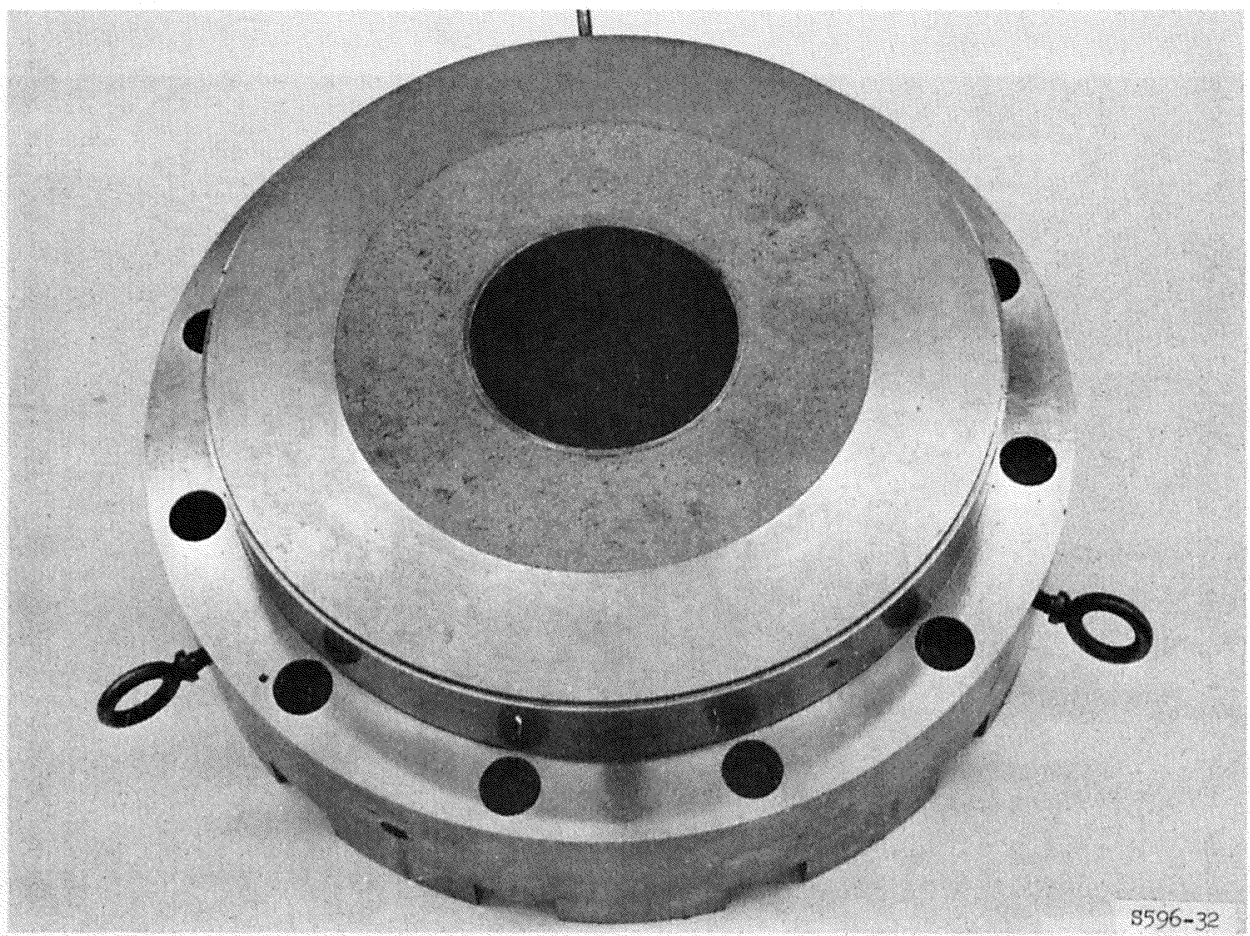

Fig. 9. Compacted sand surrounding undisturbed specimen in soil container for 10-in.-diam test device

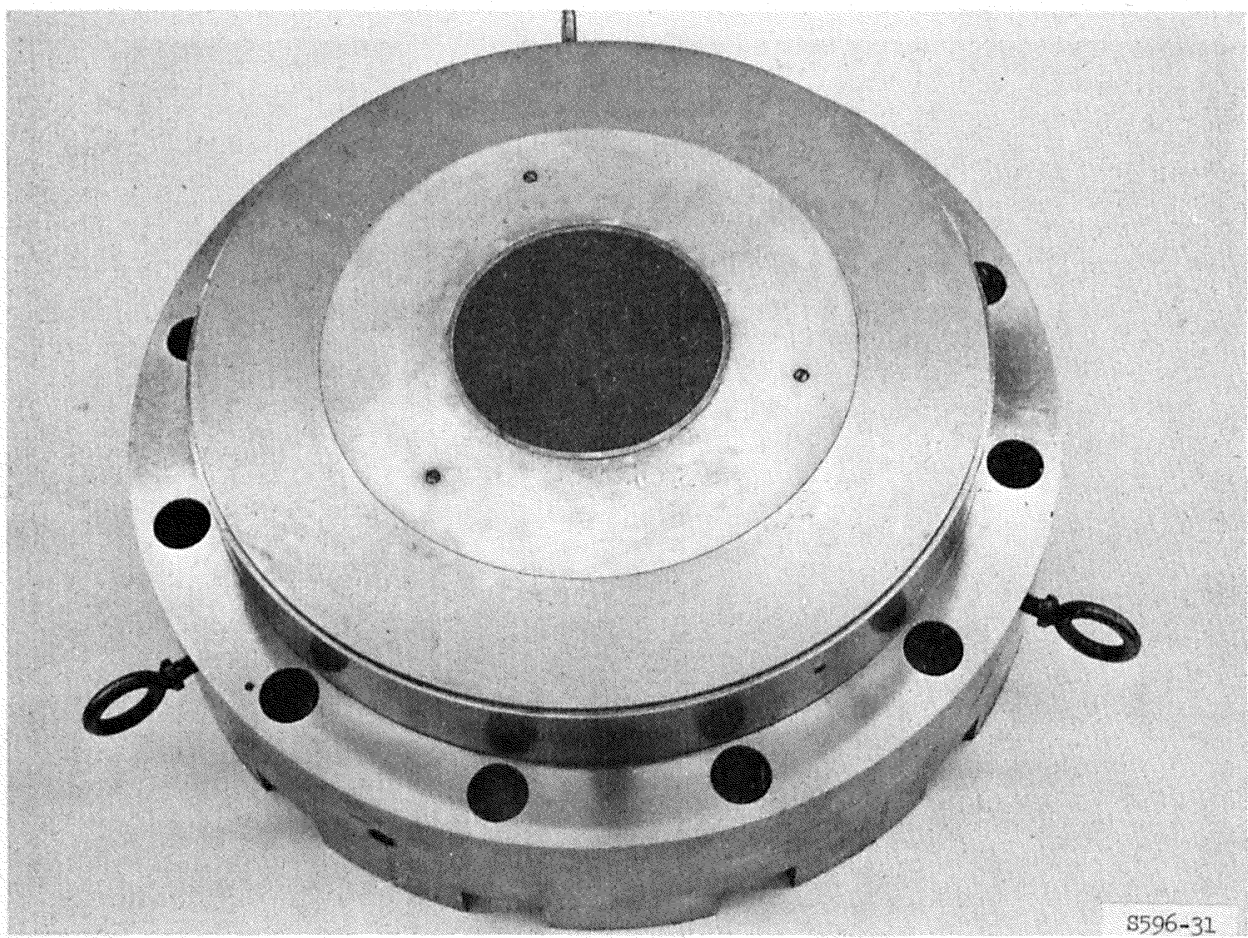

Fig. 10. Steel doughnut surrounding undisturbed specimen in soil container for 5-in.-diam test device 


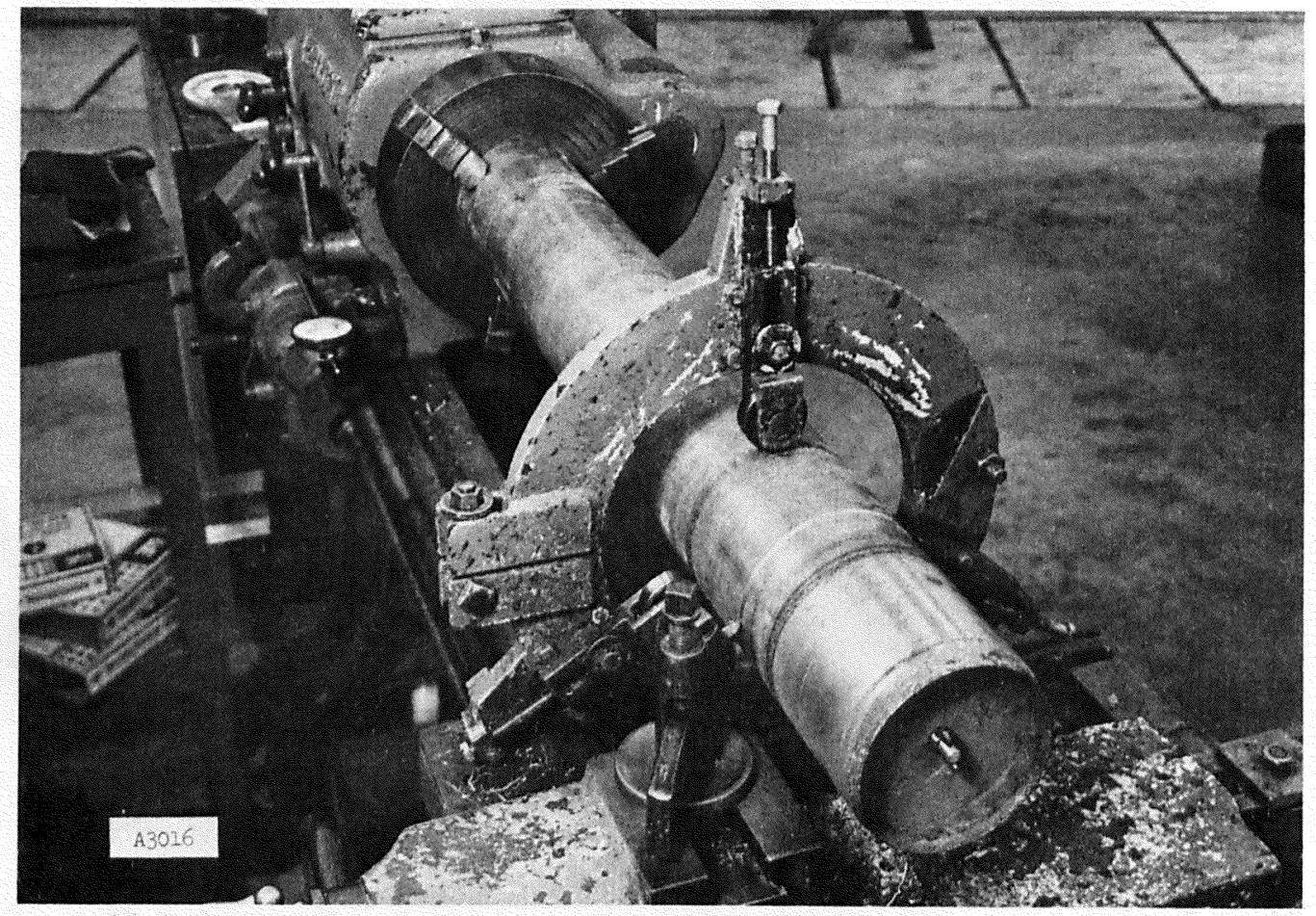

Fig. 11. Shelby tube chucked in lathe for first rough machine cut



Fig. 12. Wire saw being used to separate soil sample after rough machine cuts through steel shelby tube 


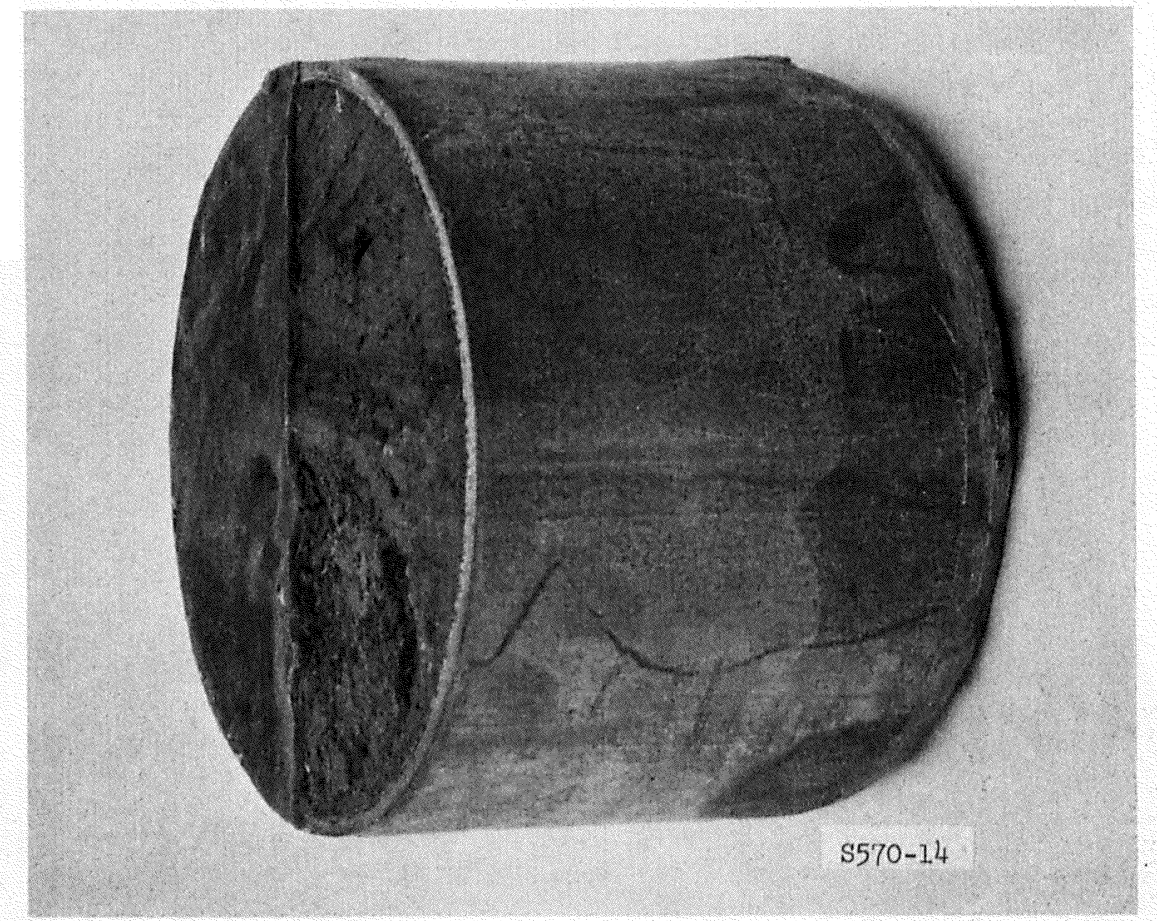

Fig. 13. Rough-cut Shelby-tube ring specimen with exposed soil partially coated with protective wax

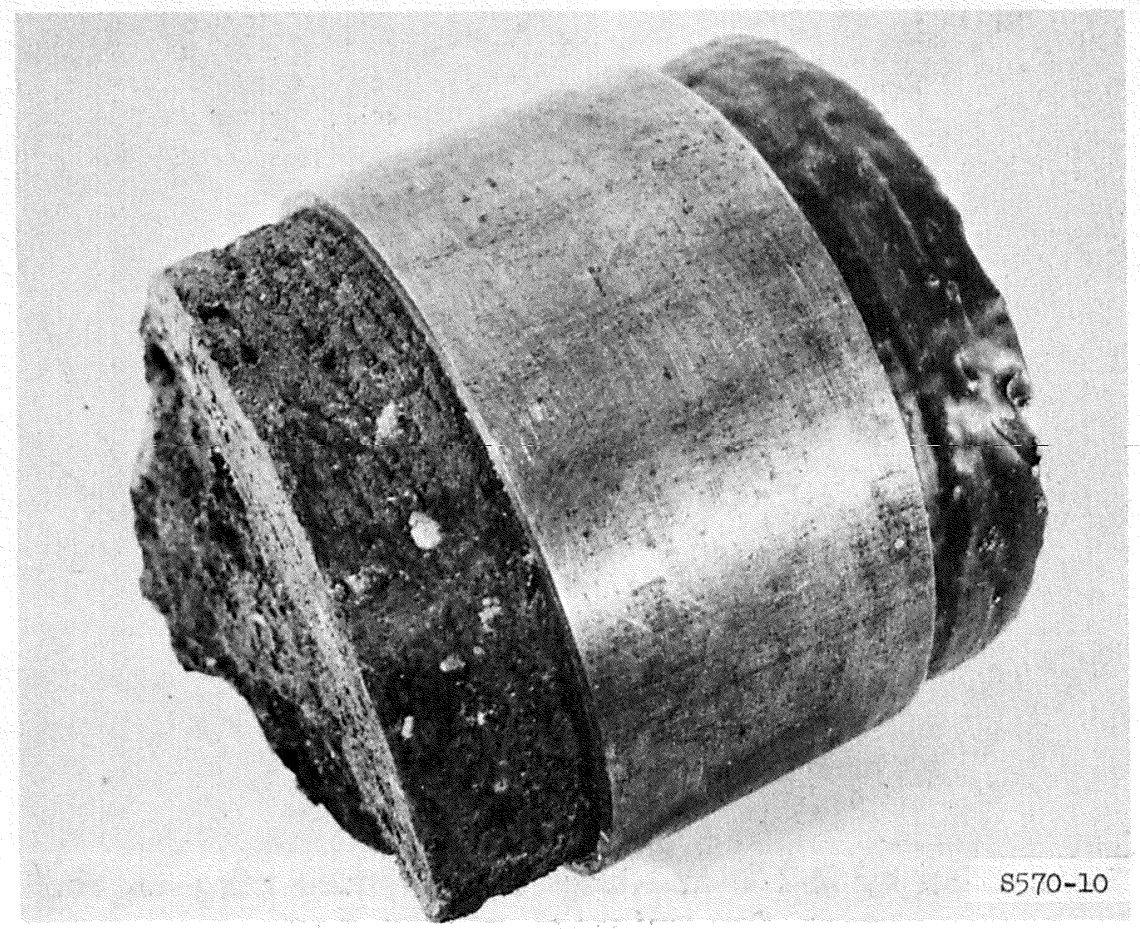

Fig. 14. Fine-machined Shelby-tube ring specimen with protruding ends of exposed and wax-protected soil 




Fig. 15. 5-in.-diam by 2-1/2-in.-high Shelby-tube ring-encased specimen ready for uniaxial strain test 


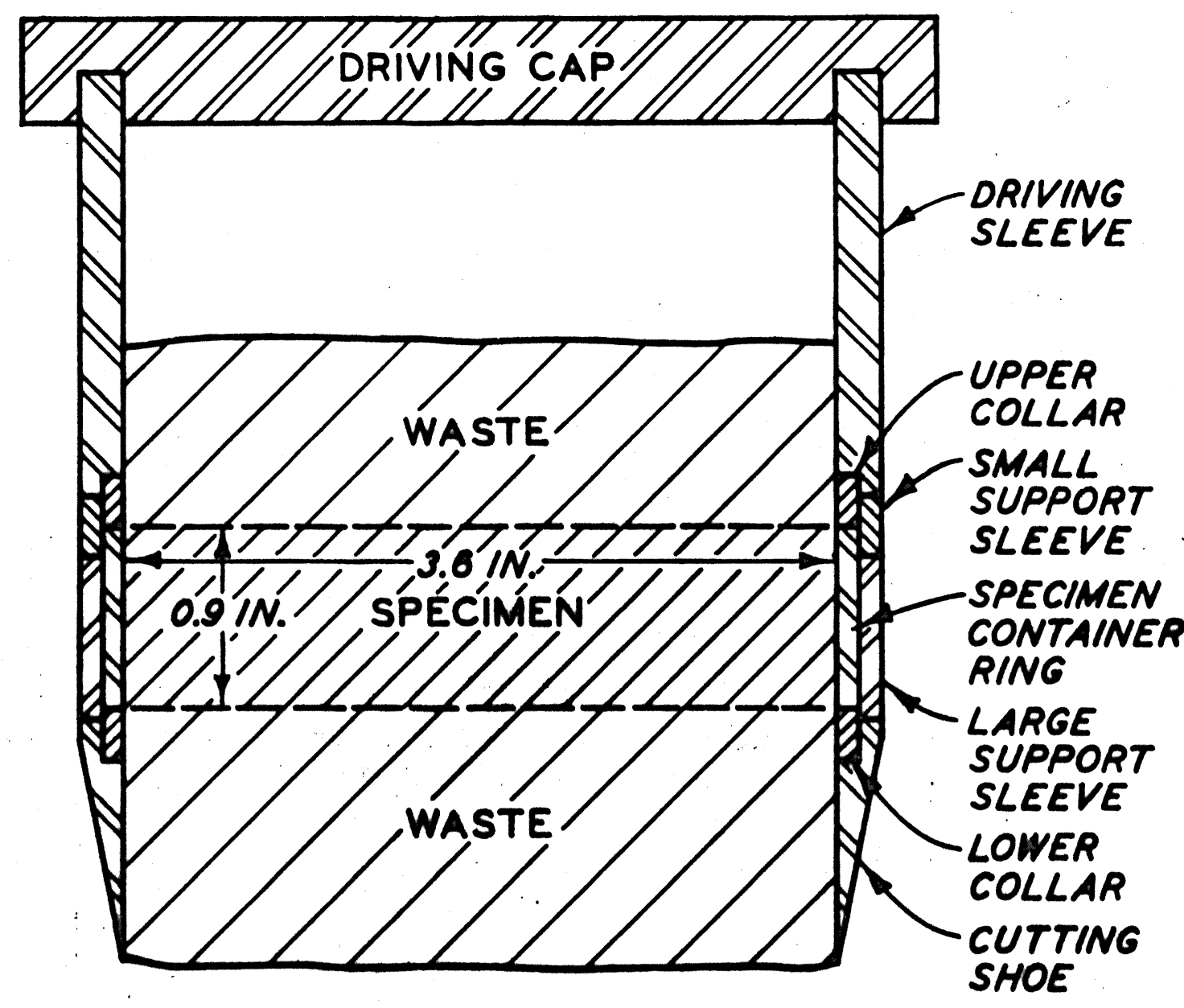

3.6-IN.-DIAM SOIL SAMPLER

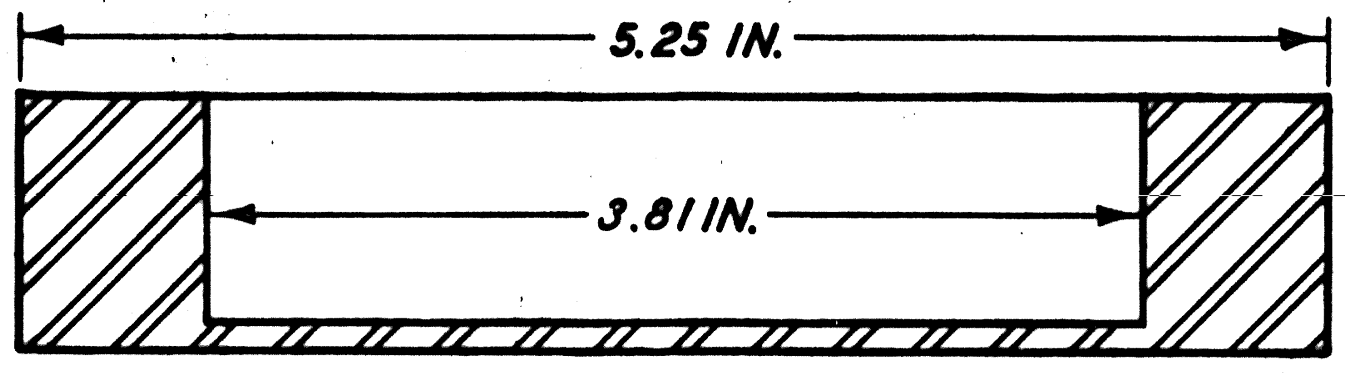

\section{ADAPTER FOR 5-IN.-DIAM UNIAXIAL STRAIN TEST DEVICE}

Fig. 16. Sampler for obtaining 3.6-in.-diam by 0.9-in.-high ring-encased soil specimens and adapter for 5-in.-diam uniaxial strain test device 


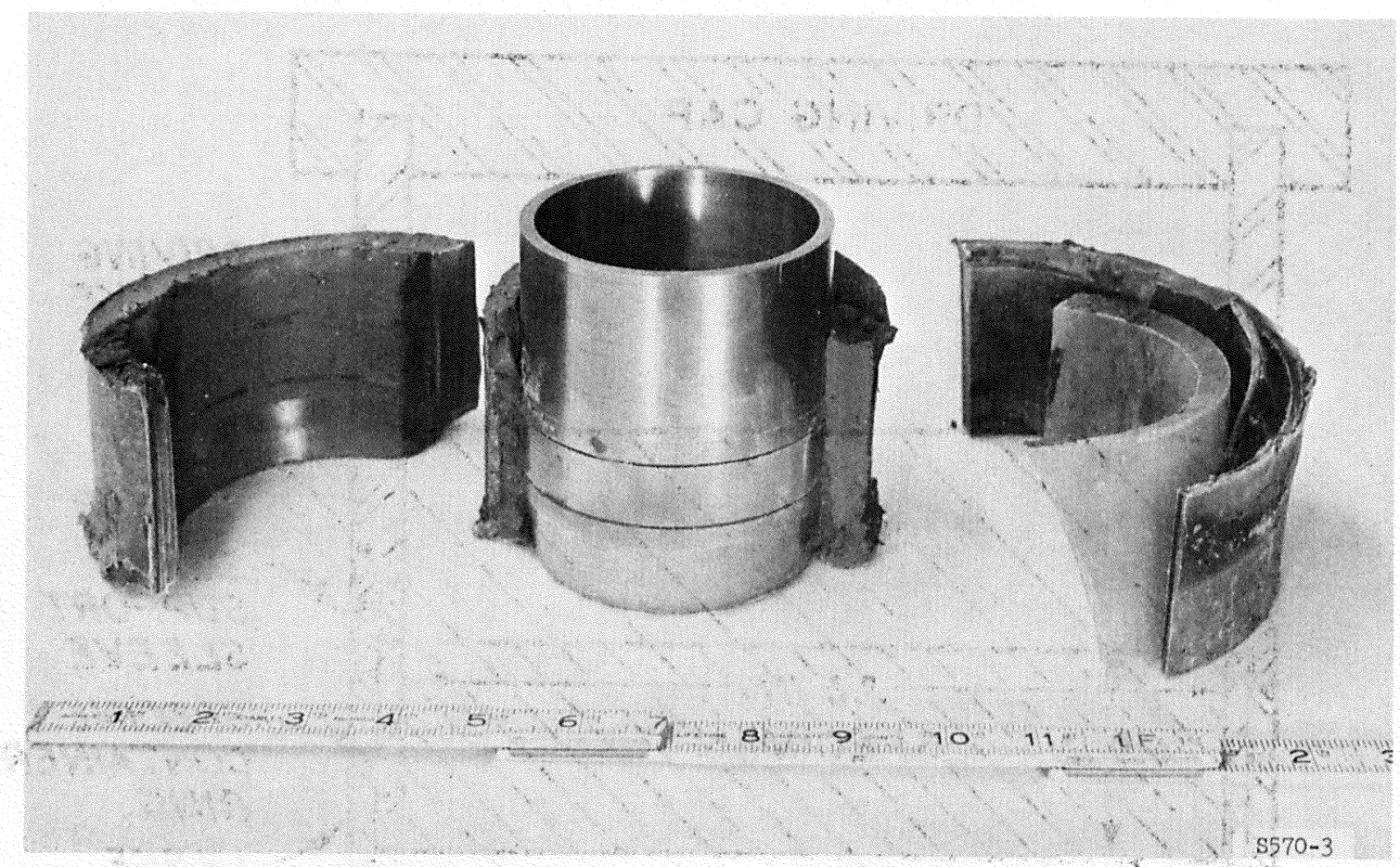

Fig. 17. 3.6-in.-diam ring sampler after jacking into wax- and cardboardencased undisturbed soil sample

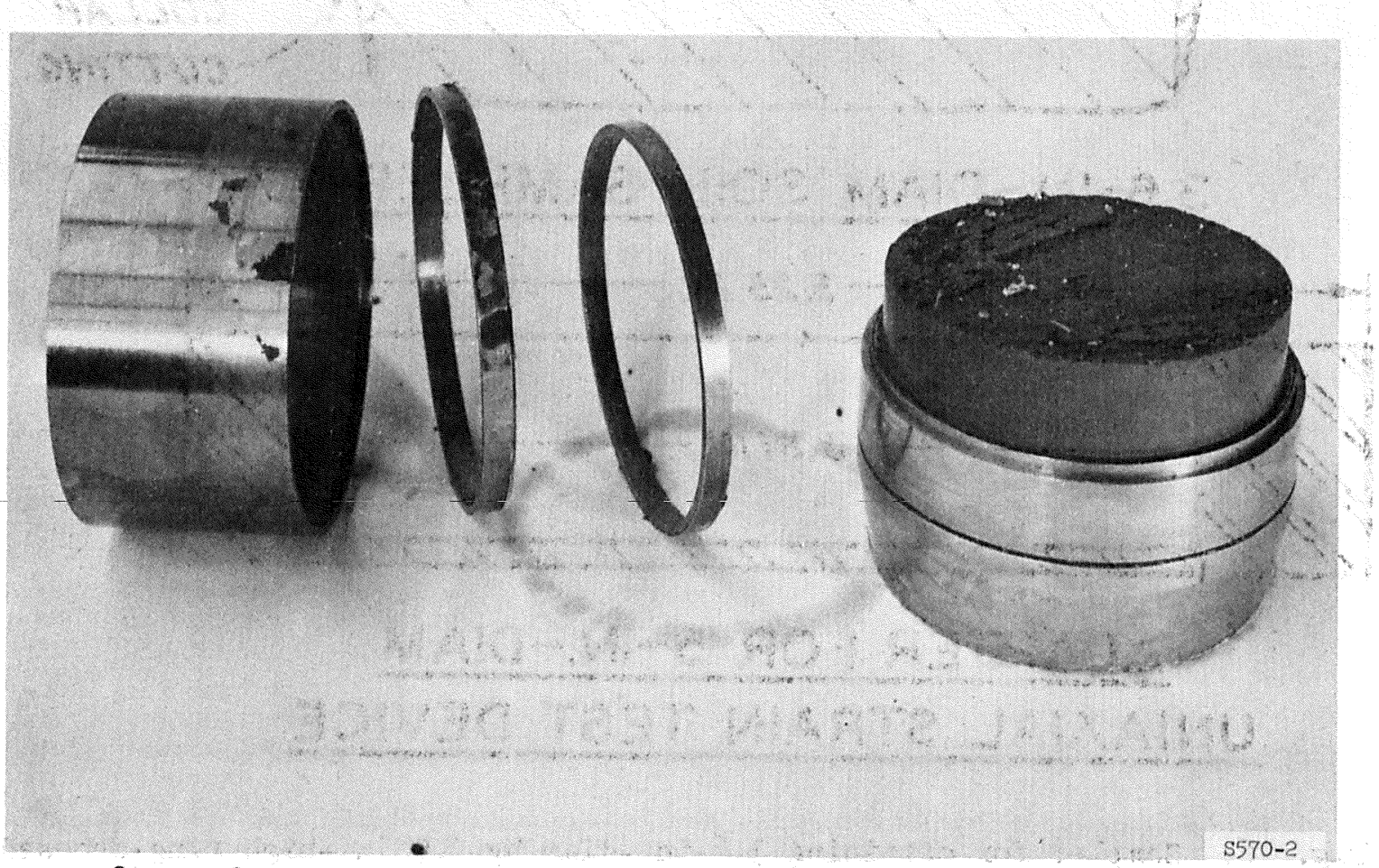

Fig. 18. 3.6-in.-diam ring sampler after removal of driving sleeve, small support sleeve, and upper collar 


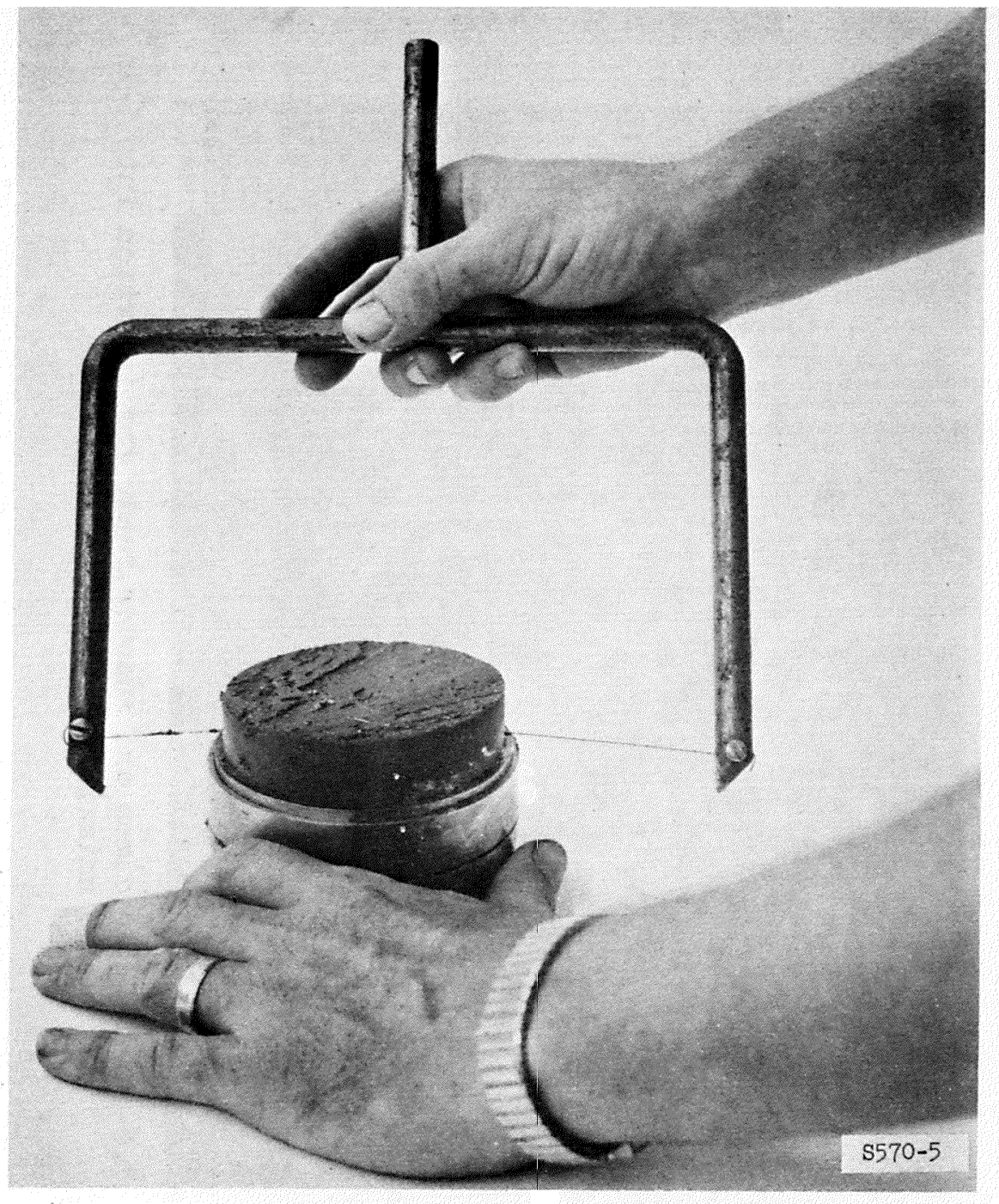

Fig. 19. Soil specimen being trimmed flush with top of 3.6-in.-diam specimen container ring

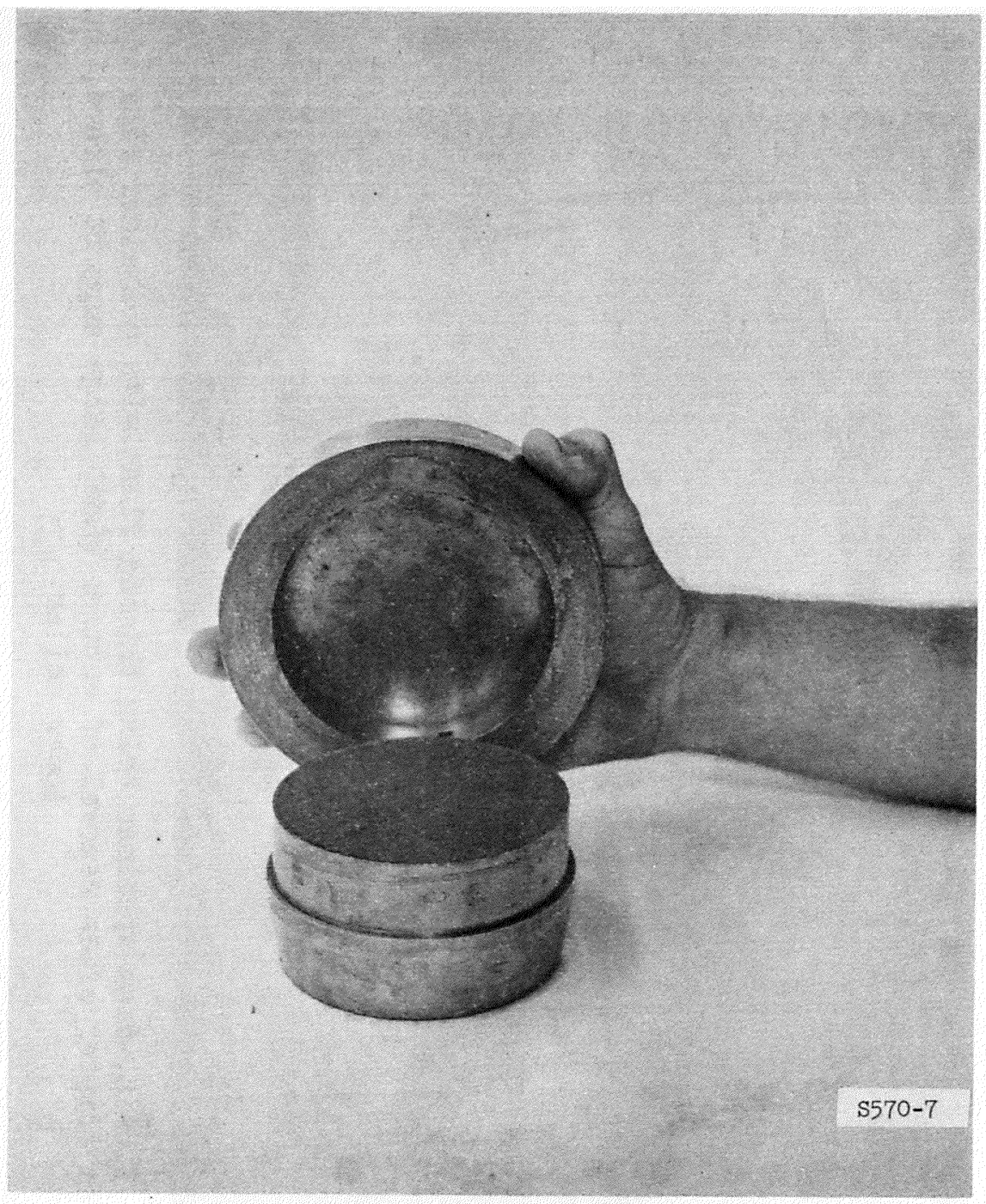

Fig. 20. Uniaxial strain device adapter being placed over 3.6-in.-diam soil specimen 


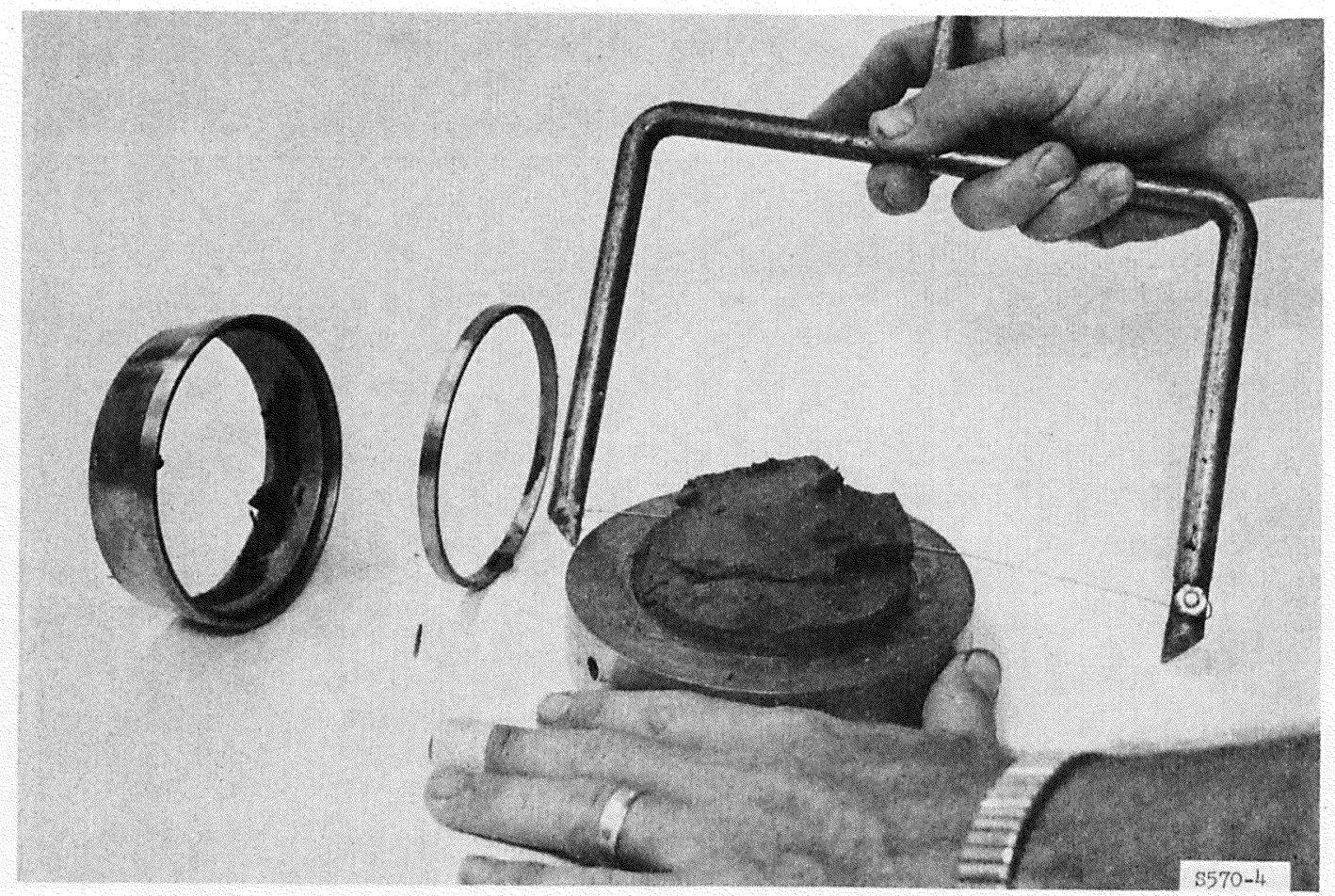

Fig. 21. 3.6-in.-diam specimen being trimmed flush with container ring and test device adapter after removal of cutting shoe, large support sleeve, and lower collar



Fig. 22. 3.6-in.-diam specimen and adapter ready for insertion into 5-in.diam uniaxial strain test device 

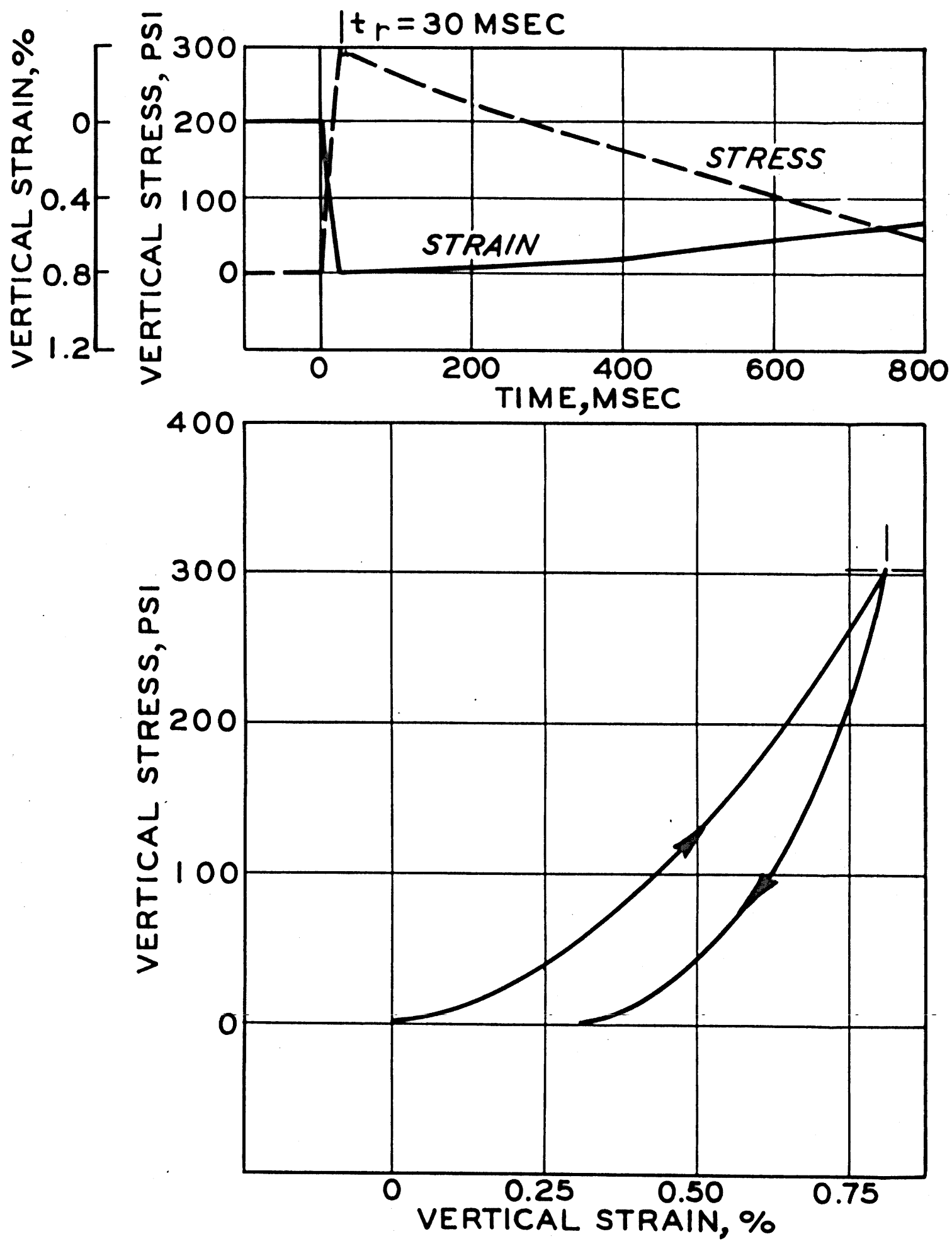

Fig. 23. Dynamic uniaxial strain test AOIPO4 on Reid-Bedford model sand (SP) at $D_{r}=93.2$ percent 

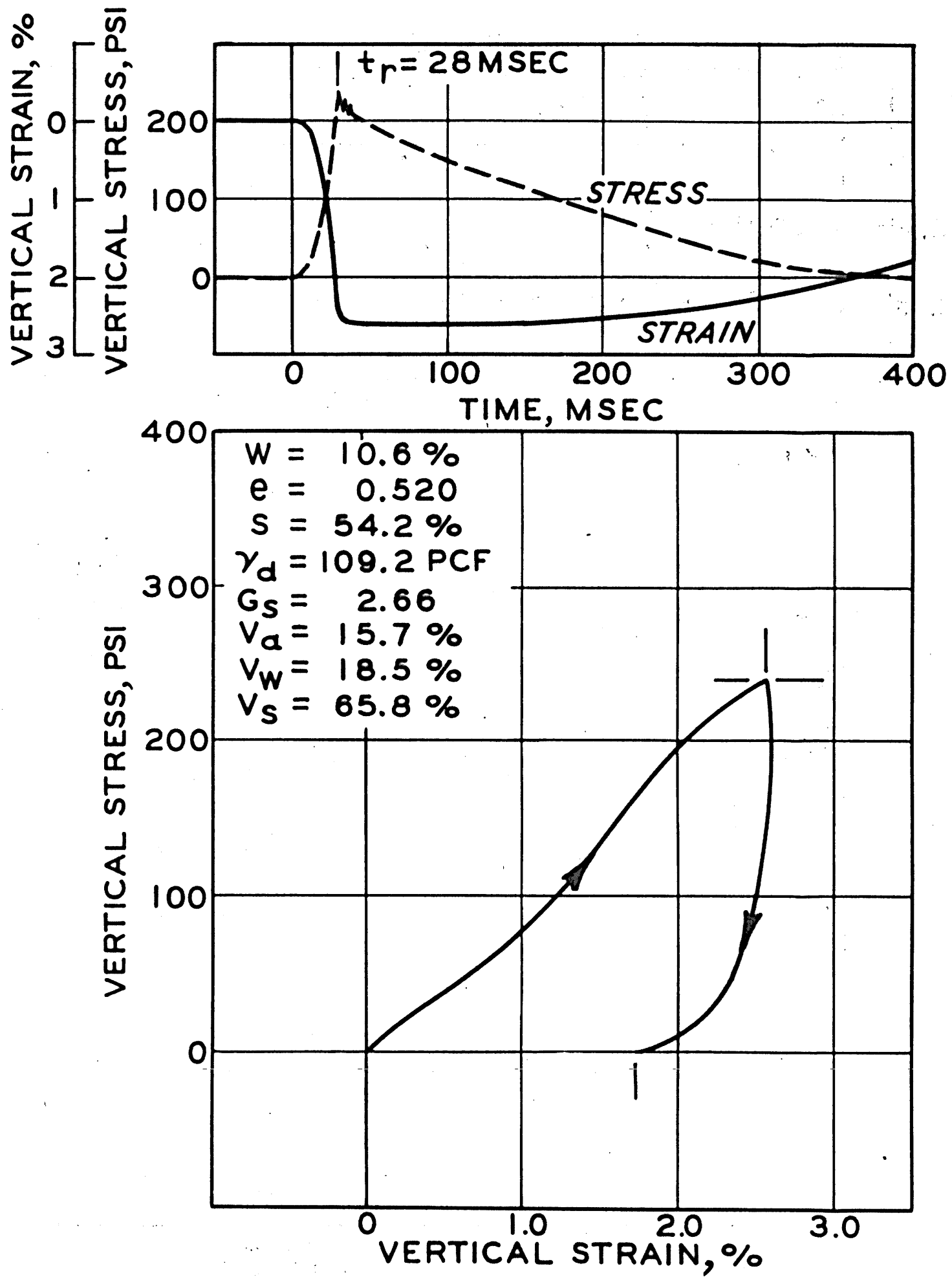

Fig. 2l. Dynamic uniaxial strain test ERDL21 on compacted tan sandy clay (CL) from Ft. Belvoir, Virginia 

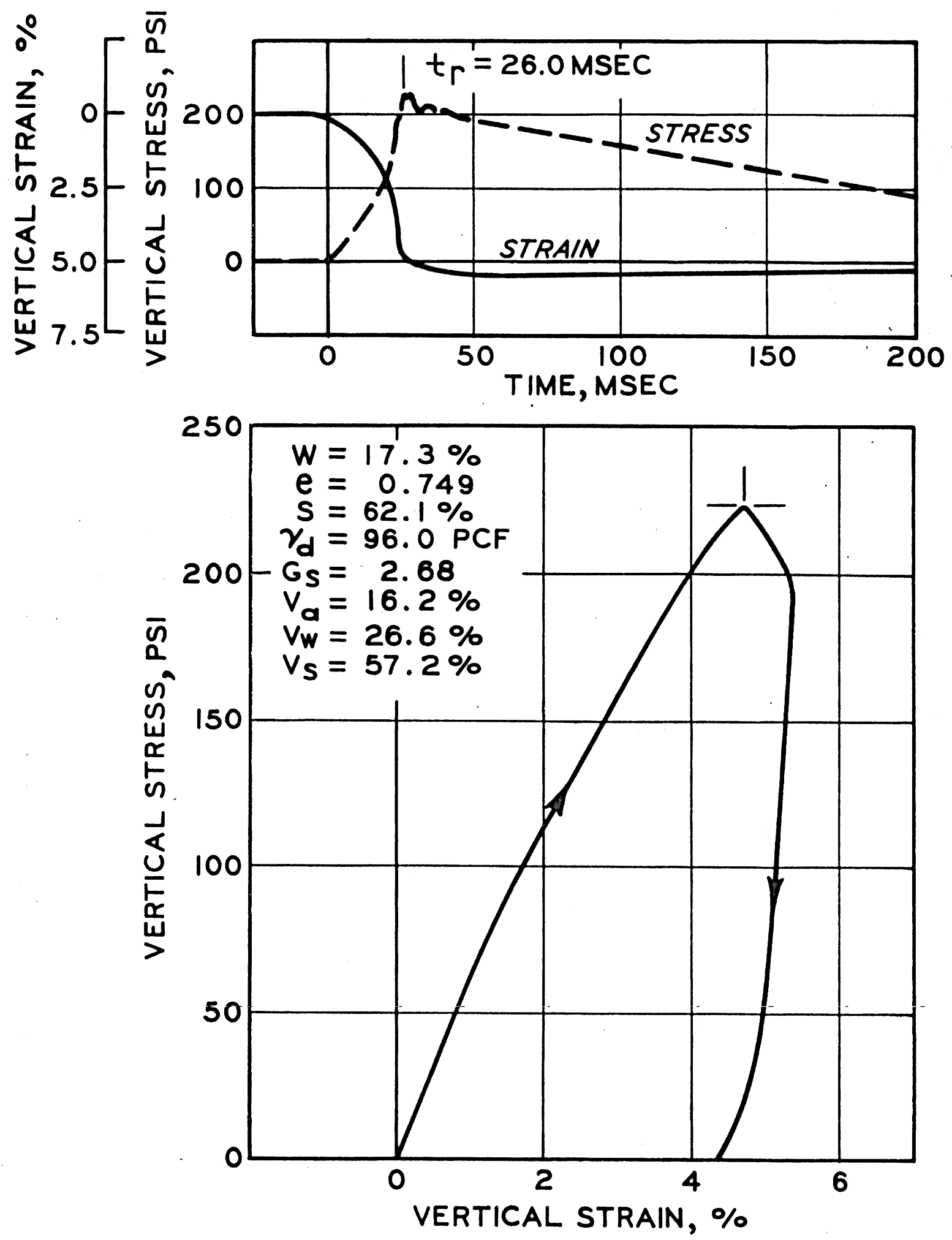

Fig. 25. Dynamic uniaxial strain test UL2 on tan silty clay (CL)-Vicksburg loess 



Fig. 26. Dynamic uniaxial strain test HV 3.7 .2 on gray sandy clay (CL) from Hope, North Dakota 



TIME, MSEC

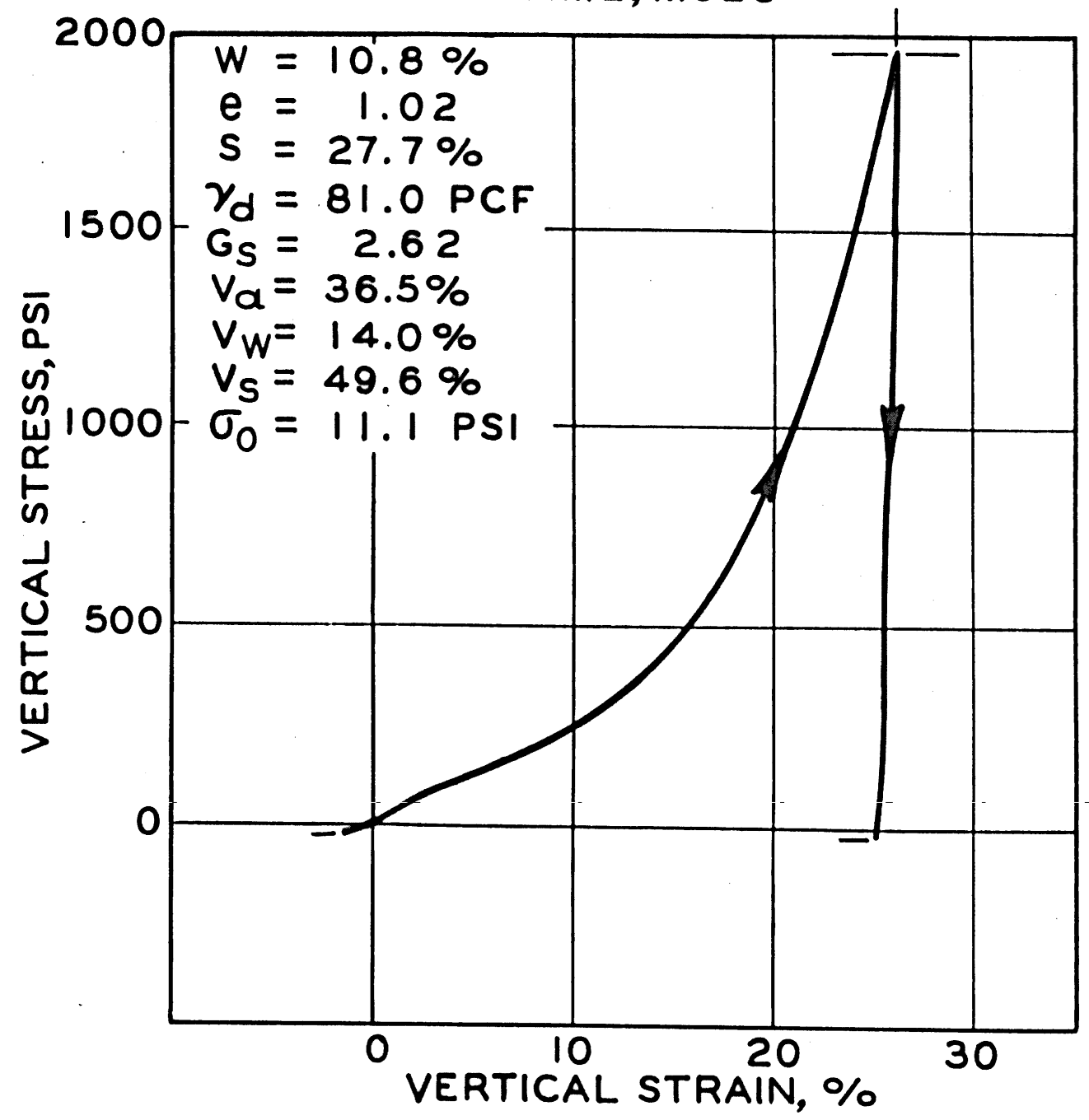

Fig. 27. Dynamic uniaxial strain test PF 7.8 .1 on brown sandy silt (ML) from Suftield, Canada 


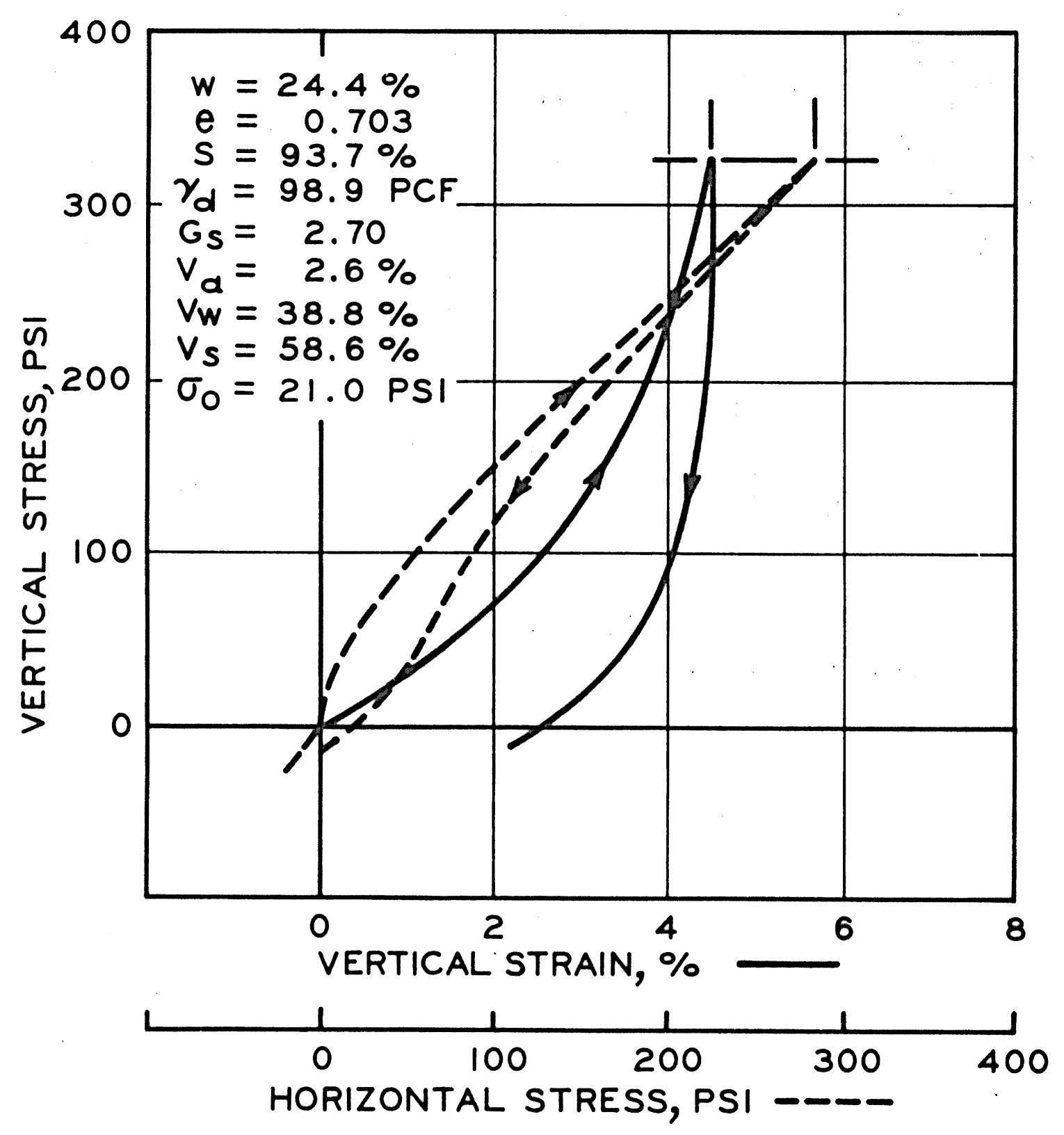

Fie. 28. Static uniaxial strain test M 1.13 .1 on brown sandy clay (CL) from Valley City, North Dakota 
Unclassified Security Classification

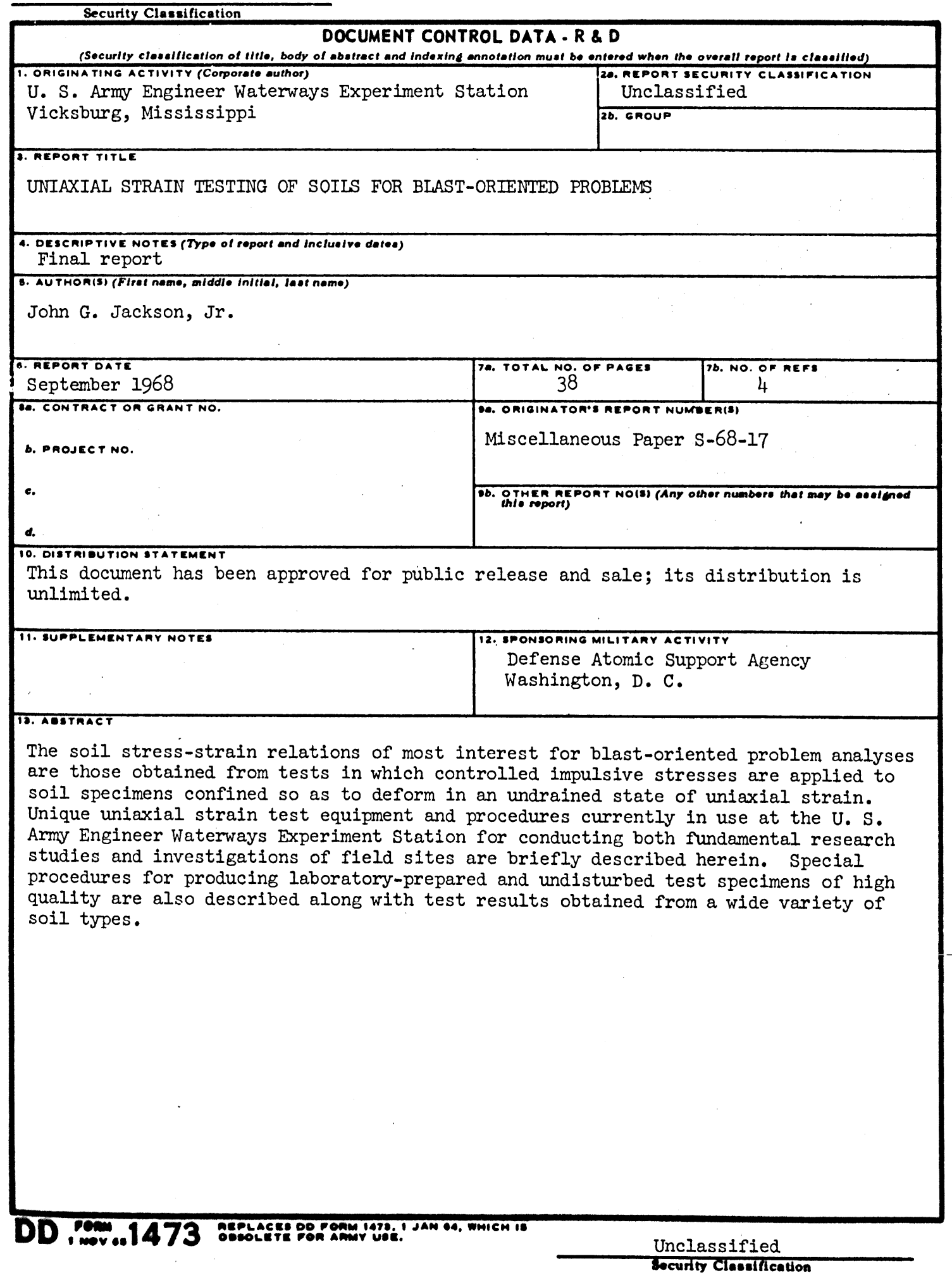


Unclassified

Security Claselfication

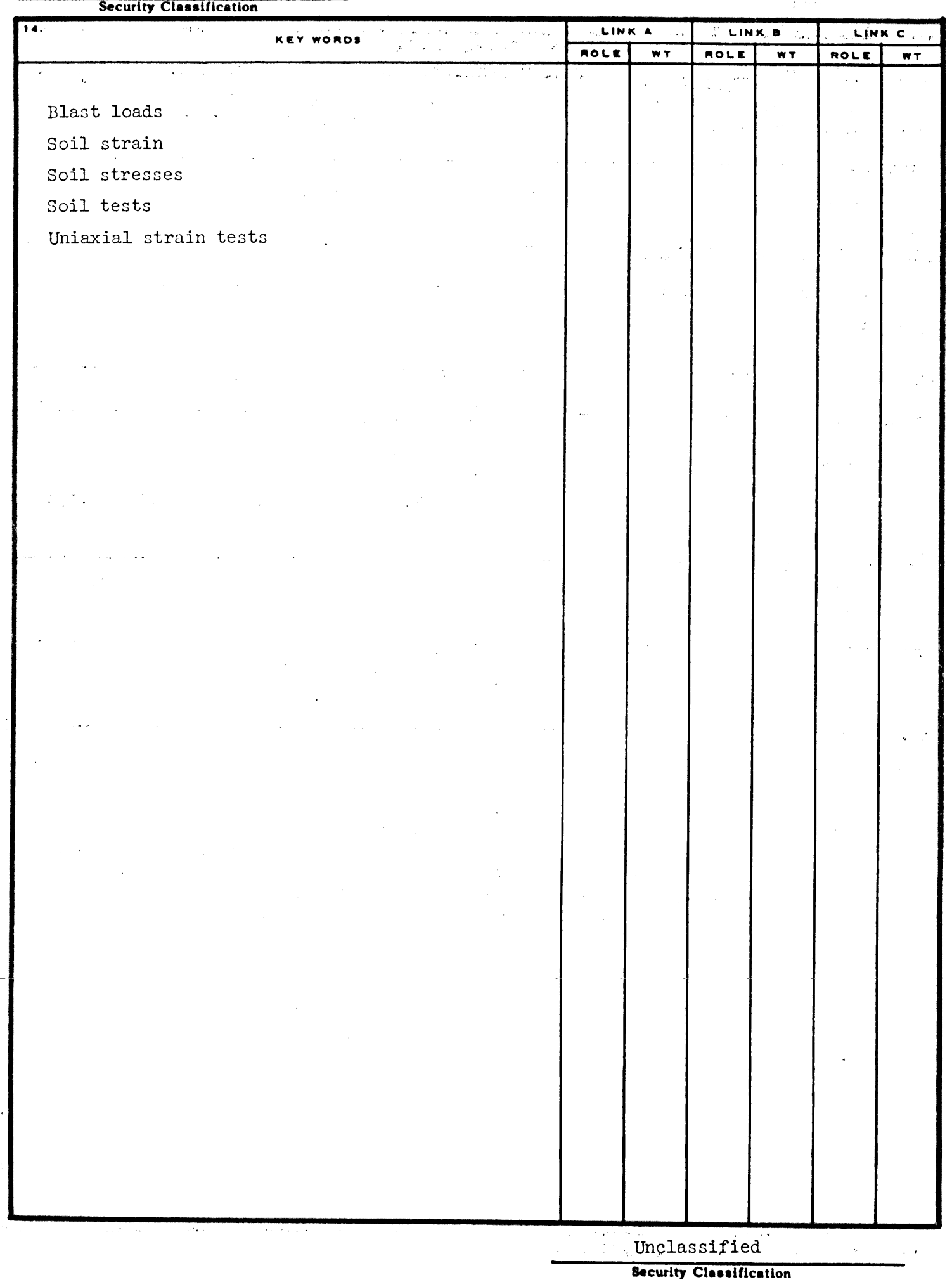

